\title{
La Compañía de Salitres de Antofagasta, Chile. El desafío de su modernización empresarial e innovación estratégica ${ }^{1}$
}

\section{The Antofagasta Nitrate Company, Chile. The challenge of its business modernization and strategic innovation}

\author{
José Antonio González Pizarro²
}

\begin{abstract}
Resumen
Se examina la Compañía de Salitres de Antofagasta, surgida en la posguerra del Pacífico, y su transformación en una empresa moderna, en cuanto su estrategia productiva y competitiva en la producción del nitrato demandó un cambio en su organización administrativa, donde la innovación tecnológica jugó un papel relevante. En tal sentido, se postula que estas reformas se verificaron entre los años 1916-1925; una vez que acrecentó el número de sus oficinas salitreras, debió encarar el desafío del salitre sintético y las opciones de inventos para modificar el sistema productivo.
\end{abstract}

Palabras claves: compañía, salitre, Antofagasta, innovación, modernización.

\begin{abstract}
This paper examines The Antofagasta Nitrate Company, which emerged after the War of the Pacific and its change into a modern enterprise since its productive and competitive nitrate strategy demanded a change in its administrative organization, where technological innovation played a relevant role. In this sense, we show that there reforms were implemented between 1916 and 1925 . Once the number of nitrate mines increased, the company had to face the challenge of synthetic nitrate and the option of inventions to change the production system.
\end{abstract}

Keywords: company, nitrate, Antofagasta, innovation, modernization.

Recibido: 18 julio 2017. Aceptado: 25 agosto 2017

1 Este trabajo es parte de los Proyectos de Investigación impulsados por el Instituto de Políticas Públicas de la Universidad Católica del Norte y contó con el financiamiento del Fondo de Innovación para la Competitividad Regional (FIC-R 2015).

2 Centro de Estudios Histórico-Jurídicos de la Facultad de Ciencias Jurídicas, Universidad Católica del Norte. Avenida Angamos 0610, Antofagasta, CHILE. Email: jagonzal@ucn.cl 


\section{Introducción}

La Compañía de Salitres de Antofagasta surgió de la división de la Compañía de Salitres y Ferrocarril de Antofagasta, verificada el 26 de febrero de 1886, dando origen a The Antofagasta (Chile) and Bolivia Railway Company Limited, propietaria del ferrocarril, y a la Compañía de Salitres de Antofagasta, a cargo de la explotación salitrera.

Los antecedentes de la Compañía de Salitres y Ferrocarril de Antofagasta hunden sus raíces con el descubrimiento de salitre por José Santos Ossa en 1866 y las amplias concesiones que otorgó el gobierno de Bolivia para la explotación del recurso a la Sociedad Exploradora del desierto de Atacama. En el devenir de la empresa encontramos la convergencia de los intereses capitalistas chilenos, principalmente de Agustín Edwards Ossandón, de José Santos Ossa y Francisco Puelma, y de los ingleses Jorge Smith, Milbourne Clark y Guillermo Gibbs y Cía. En el período de la década de 1860 la participación en las acciones fue mayoritariamente chilena. Sin embargo, el descubrimiento de plata en Caracoles, en marzo de 1870, modificó las finalidades de la entonces empresa Milbourne Clark y Cía, surgida en 1869. La transformación de la red de líneas ferroviarias, al calor de las actividades argentíferas mencionadas, condujo a la construcción del ferrocarril que unió en 1872 a la ciudad de Antofagasta y Salinas, próximo al mencionado yacimiento. Con este proyecto surgió la Compañía de Salitres y Ferrocarril de Antofagasta, donde los capitales de chilenos y británicos prosiguieron con ambas actividades, teniendo su asiento en Valparaíso. La figura de Agustín Edwards Ossandón fue la que predominó, con el 41,94\% de la propiedad, seguido de W. Gibbs, con el 28,7\%, y Francisco Puelma y otros con el 25,6\%, existiendo variaciones menores en los porcentajes, según los autores que han examinado el tema (Díaz, 2005, p. 134; Blakemore, 1996, p. 32; Nazer Ahumada, 2000).

Entre los años 1872 y 1879 , la compañía estuvo sujeta a los vaivenes de las relaciones diplomáticas entre Chile y Bolivia, que, si bien habían suscrito en el Tratado de 1866, mantenían criterios dispares sobre las fronteras, la explotación de los recursos y la cuestión de los impuestos, nuevos convenios en torno a dar certeza a los capitales chilenos en el desierto de Atacama, como fue el Tratado de 1874, hasta recibir la amenaza por parte del gobierno de Sucre del remate el día 14 de febrero de 1879.

Sin embargo, debe verse en la trama de acontecimientos en el desierto de Atacama la combinación de variados intereses económicos, políticos y diplomáticos, que en gran medida se sintetizaron en los accionistas mayoritarios de la compañía y su amplia red de influencia en la política chilena (Mayo, 1979; Ravest Mora, 1983; O’Brien, 1980; Nazer Ahumada, 2000; Querejazu Calvo, 2001; Ortega, 1984; Alonso, 2015; Villegas, 2015).

Reivindicado el territorio del desierto de Atacama por Chile, mediante la ocupación militar de Antofagasta el 14 de febrero de 1879, la compañía prosiguió su influencia en el gran despoblado, pero ahora, como hemos indicado en líneas superiores, separada en 1886 en dos. Los capitales ingleses tomaron el control estratégico de la Compañía de Ferrocarriles y las inversiones chilenas prosiguieron con la propiedad de la Compañía de Salitres. Los descendientes de Edwards, Ossa, Puelma, entre otros, se mantuvieron como accionistas en la empresa.

Importa destacar que la Compañía de Salitres se constituyó en la principal empresa chilena en la explotación del nitrato de soda, concentrando sus instalaciones industriales mayoritariamente en el denominado cantón Central o boliviano. La presencia temprana del ferrocarril en el cantón Central lo benefició respecto a los otros cantones de la región de Antofagasta (González Miranda, 2010). Al sur del despoblado, José Antonio Moreno había abierto las posibilidades de explotación del nitrato en lo que se denominó el cantón de Taltal (San Francisco, Ballester, Sepúlveda, Lasnibat, Sepúlveda, 2009).

Durante el siglo XIX, la Compañía de Salitres de Antofagasta explotó las oficinas Salar del Carmen y Pampa Central. La Oficina Salar del Carmen (en Carmen Alto), a $33 \mathrm{~km}$ de Antofagasta, funcionó entre 1869 y 1884 , siendo reiniciada solo para extracción del salitre en 1888. Un testigo de la época, Isaac Arce, puntualiza que dejó de funcionar 
hacia fines de siglo, reiniciándose sus fuegos en 1905 (Arce, 2004, p. 402). Arce, que trabajó en la compañía entre 1881-1906, se desenvolvió como jefe de Pulpería y administrador del campamento de Pampa Alta (kilómetro 150 del F.C.A.B.) y en las oficinas Salar del Carmen y Carmen Alto, precisando que en Carmen Alto se construyó la Oficina Francisco Puelma, y en Pampa Central, la Oficina Agustín Edwards (Arce, 1940).

Las extracciones de caliche de Salar del Carmen y Pampa Central fueron elaboradas en la oficina de Antofagasta, establecida en junio de 1877, por el problema de la borra en el caliche de Salar del Carmen (Crozier, 1993, pp. 190-191; Díaz, 2005, pp. 127-129). Desde 1886, la Compañía de Salitres de Antofagasta cerró su administración central en Antofagasta y la trasladó a la ciudad de Valparaíso. Allí sesionaría su Consejo Directivo.

Nuestro objetivo, empero, es centrar el análisis en los ańos de la posguerra que trajo la noticia de la invención del salitre sintético como la principal amenaza a la producción nacional, y la imperiosa necesidad de encontrar tecnologías que pudieran reducir los costos de producción hasta plantearse la enajenación de la compañía a mediados de la década de 1920. Consideramos que es en este lapso cuando ésta comienza su transformación hacia una modernización de su estructura, no solamente por los antecedentes que hemos esbozado, sino por la expansión en su número de oficinas salitreras, la multiplicación de la mano de obra y la conveniencia de incorporar un alto grado de profesionalización, no solo en la administración empresarial, sino en la vinculación de científicos o ingenieros especialistas en la búsqueda de innovación tecnológica. Un tema que ha comenzado a suscitar un gran interés en América Latina (Guajardo, 2014).

Nuestra hipótesis es que la Compañía de Salitres de Antofagasta no solo fue la principal empresa salitrera chilena, sino probablemente una de la más importantes de la época en el país, al incorporar estándares internacionales en su manejo empresarial, diferenciando la gestión de la administración y la gerencia con la titularidad de la propiedad, adecuando su organización empresarial a los fines de su estrategia productiva, que consideró innovaciones variadas para su logro.

Para el desarrollo del tema hemos contado con los antecedentes bibliográficos más pertinentes, además de la rica documentación del Fondo del Salitre del Archivo Nacional de la Administración, fundamentalmente las actas del directorio de la Compañía de Salitres de Antofagasta.

\section{La Compañía de Salitres de Antofagasta y su consolidación empresarial}

J. R. Brown (1963) ha señalado que las combinaciones eran típicas de las organizaciones comerciales de la época. No obstante, las denominadas combinaciones salitreras afectaron los ingresos del gobierno, la fuerza de trabajo del país y a la influyente clase alta agraria y capitalista. Como toda empresa de importancia, la Compañía de Salitres de Antofagasta -todavía unida a la de los ferrocarriles- participó activamente en la creación de las combinaciones salitreras, la primera en 1884 , como parte de la defensa de los empresarios salitreros que ante la alarmante producción de nitrato deseaban determinar cuotas de producción y controlar la venta en el mercado europeo, frente a los intentos que pretendían restringir la gravitación de las empresas extranjeras, la especulación y regular la venta del nitrato. La falta de innovaciones tecnológicas en sus industrias -durante la hegemonía del sistema Shanks- hizo más urgente esta defensa corporativa frente a la competencia del salitre nacional en los mercados mundiales (González Miranda, 2013). Para principios de 1900 la compañía no estaba tan segura de participar en otra combinación, cuando todavía estaba en vigencia la tercera Combinación (FSA, v. 4: 1), pero finalmente cambia de postura en noviembre de 1905, adhiriéndose a la nueva Combinación en marzo de 1906 con una cuota inicial de 900.000 qq para sus oficinas de Antofagasta y Carmen Alto (FSA, v. 5: 8). Era el ingreso a la quinta Combinación, que funcionó entre abril de 1906 y abril de 1909. La percepción gubernamental se había modificado: "the government's recognition that a combination would bring 'secure and normal' conditions to the industry" (Brown, 1963, p. 240) 
Durante el primer lustro del siglo XX -en 1903funcionaban en Antofagasta cinco oficinas: Antofagasta, Salar, Central, Pampa Alta y Lastenia (Memoria, 1904, p. 71), pero al inicio de 1904 solo estaban operativas dos de ellas, lo que contrastaba con las cinco en Taltal y las seis en Tocopilla, resultado primordial de las inversiones alemanas principalmente de H. B. Sloman y Folsch \& Martin (Memoria, 1904, p. 33). Los capitales germanos comenzaron a delinear el cantón del Toco, a partir de 1890 (Capaldo, Damm, Odone, 2010).

Las dos oficinas de Antofagasta (correspondiente al cantón Central o boliviano) eran de la Compañía de Salitres de Antofagasta. No obstante, Semper y Michells (1908, p. 148) indican que para 1901 funcionaba solo una oficina salitrera en el cantón Central. La situación era delicada incluso estando en vigencia la Combinación. La Delegación Fiscal de Salitreras advertía, en 1904, las dificultades para la industria nacional:

\begin{abstract}
Llegado á producirse el agotamiento de nuestros depósitos se produciría un trastorno en el mundo entero, si antes la ciencia y la industria no les ha suministrado otro elemento, con que sustituir al nitrato, que lleve la fertilización á los campos agotados. Encontrado el medio de producir barato el salitre artificial y establecida la competencia con la industria que esplota nuestros depósitos naturales, el primero que tendría que sufrir sus consecuencias sería la Nación (Memoria, 1904, p. 40).
\end{abstract}

En la élite y la opinión pública esto se traducía en una mirada ambivalente sobre el salitre: considerar el recurso como una maldición o una bendición para los destinos del país (Tower, 1913, p. 209).

La compañía también emprendió una serie de obras en el puerto de Antofagasta. En 1904 solicitó del gobierno un terreno de playa para construir un gran muelle, bodegas y otros depósitos. Las diligencias comenzadas en el mes de enero lograron su cometido en diciembre al serle concedida la petición (FSA, v. 5: 2)
La situación de la compañía comenzó a modificarse en los años siguientes, en el bienio 1906-1907, con la creación de nuevas oficinas salitreras -como lo testimonia Isaac Arce en su obra- en la región de Antofagasta, que coincidió con el florecimiento industrial en la zona, el arribo de miles de enganchados nacionales y la fuerte inmigración extranjera que se experimentó en Antofagasta, alcanzando en 1907 la mayor presencia extranjera en toda la historia regional.

Cabe señalar que los terrenos de la compañía en el Salar del Carmen habían concitado desde el año 1904 un inusitado interés en su arrendamiento. El político Gonzalo Bulnes, en su faceta empresarial, planteó un alquiler para construir una oficina salitrera cuyas instalaciones, al término de 20 años, pasarían a poder de la compañía (FSA, v. 5: 3). Al año siguiente, la Compañía Salitrera El Boquete pretendió lo mismo. Ante ambas ofertas, la compañía se pronunció negativamente.

Tal interés en sus terrenos salitrales movió al directorio de la compañía, considerando su incorporación en la nueva combinación salitrera, a conformar nuevas sociedades, en el segundo semestre de 1905. Así, organizó la Compañía Salitrera La Araucana, en el mes de julio, suscribiendo un millón ochocientas mil acciones y transfiriendo a la nueva sociedad importantes terrenos salitrales. En octubre ya contaba con un significativo número de accionistas radicados en Santiago (FSA, v. 5: 4). En el mes de agosto, conjuntamente con la firma Inglis Lomax, suscribió una escritura para establecer la Compañía Salitrera El Loa, haciendo la misma operación con parte de sus estacas salitreras, mientras Inglis pagaba 22 mil libras esterlinas por un paquete de 20 mil acciones (FSA, v. 5: 5). La Compañía Salitrera El Loa, para el año 1914, era propietaria de las oficinas salitreras Anita, Candelaria, Curicó y Luisis, todas en el cantón Central y con domicilio en Valparaíso (Silva Narro, 1914, pp. 192-196). En 1913 la Sociedad Baburizza, Bruna y Lukinovic adquirió la Compañía Salitrera Progreso de Eduardo Cavallero, que había levantado las oficinas Filomena, en 1904, y Ausonia y Aconcagua en 1908 (González Miranda y Sossa, 2011). 
El repunte del precio del salitre de los ańos 1904 y 1907 hizo que la región de Antofagasta experimentara el mayor crecimiento de oficinas salitreras, pasando de 12 a 44, según registraba el Ministerio de Hacienda en su Memoria de 1907 (Brown, 1963, p. 241). R. F. Penrose, quien visitó en 1907 la zona salitrera, estimaba cerca de 100 oficinas en Tarapacá y unas 50 en Antofagasta (Penrose, 1910, p. 26).

La compañía aprovechó la bonanza. Modificó el nombre de la Oficina Carmen Alto por Francisco Puelma, en 1907, para homenajear a uno de los más insignes empresarios, aunque en 1908 siguió figurando otra Oficina Carmen Alto (Silva Narro, 1909). La Oficina Puelma llegó a contar con 1.838 trabajadores. La decisión de cerrar la máquina de elaboración de salitre en Antofagasta le permitió en 1907 la construcción de la Oficina Agustín Edwards, que inició su producción en 1909. Se trató de una oficina pequeña, donde trabajaban 700 operarios. De similar tamaño fue la Oficina José Santos Ossa, que comenzó sus operaciones en 1910 con 610 trabajadores, la que sufrió daños por un incendio en 1918. La Oficina Aníbal Pinto, construcción a cargo del ingeniero Schröder, comenzaría a funcionar a fines del año 1912 (FSA, v. 12: 1). Sería la de mayores dimensiones, con 1.658 operarios. Ese mismo año la Oficina Arturo Prat comenzó sus operaciones con sus 1.180 trabajadores. Dos instalaciones más construyó la compañía: la Oficina Carlos Condell en 1914 y la Oficina Sargento Aldea en 1915. Esta última estuvo relacionada con la adquisición, en el mes de setiembre, de la Oficina Riviera (FSA, v. 11: 1), rebautizada como Sargento Aldea. La operación de compra fue mediada por el Banco de Chile. La Oficina Riviera tenía en 1907 una población de 923 personas (Comisión, 1907, p. 77).

Recién en 1918, la Oficina Condell contó con una Casa de Yodo, fundamental para fijar su cuota de producción. Según las actas del directorio de la compañía, todavía en noviembre de 1922 se seguían implementando las construcciones de las oficinas Condell y Aldea, "para que queden listas para ponerlas en marcha" (FSA, v. 16: 1).

Si bien el primer año del conflicto mundial significó el bloqueo de venta del nitrato a Alemania, los tres últimos años fueron de gran expansión de las ventas del fertilizante, con un repunte en su precio (Vidal, 1933, p. 25; Couyoumdjian, 1974-1975, pp. 17-32; Miller, 2015, p. 97). En 1915 se decidió la compra de la Oficina Pampa Rica, por un valor de 10.000 pesos, "incluso los terrenos que nada valen” (FSA, v. 11: 2). Pampa Rica contaba con una población de 1.378 personas en 1907 (Comisión, 1907, p. 77). Desde ese ańo la compañía estuvo centrada en la explotación del estacamento Salinas Norte, con el propósito de levantar allí otra oficina salitrera. Ésta se construyó en 1919 y recibió el nombre de Oficina José Francisco Vergara, que se transformó en la usina más importante de la compañía, por su capacidad productiva (González Pizarro, 2017, p. 139). Cabe acotar que la antigua Oficina Carmen Alto sirvió para la instalación de la Oficina Francisco Vergara y la Oficina Pampa Central para la de Agustín Edwards (Arce, 2004, pp. 399, 403). La Oficina José Francisco Vergara se instaló en terrenos cuyos derechos desde abril de 1872 fueron reconocidos por el Fisco a la compañía, en diciembre de 1917 (FSA, v. 13: 1). En marzo de 1923 se consideró terminada la Oficina José F. Vergara (FSA, v. 16: 2).

En el avalúo de sus propiedades llevado a cabo por la compañía en 1918, la Oficina Aníbal Pinto tenía un valor de 4.500.000 pesos, seguida de la Oficina Prat con 4 millones, la Oficina Puelma con 3.400.000 pesos, la Oficina Vergara con 3.353,402 pesos, las oficinas Edwards, Ossa y Aldea con 2.500 .000 pesos cada una y la Oficina Condell con 2 millones de pesos (FSA, v. 13: 2).

Isaac Arce, importante empleado de la compañía, la describió en esos años como "[e]mpresa esencialmente chilena, y todos veíamos con legítimo orgullo que empresa de tal magnitud, estuviera administrada por chilenos y que todos sus empleados, desde los más altos jefes, fueran chilenos" (Arce, citado en González Pizarro, 2005, p. 19).

A su vez, Ricardo Latcham ponderó "los buenos campamentos, hechos a gran costo y con toda clase de servicios" y cómo de 1908 a 1910 fueron reemplazados por otros de superior calidad en menos de 10 años (Latcham, 1926, p. 74). 
Tabla 1. Población general en las oficinas salitreras de la Cía. De Salitres de Antofagasta.

\begin{tabular}{|l|c|c|c|}
\hline Oficina Salitrera & Población Hombres & Población Mujeres & Población Total \\
\hline Francisco Puelma & 719 & 528 & 1.247 \\
\hline Agustín Edwards & 413 & 397 & 1.165 \\
\hline José Santos Ossa & 986 & 679 & 2.159 \\
\hline Aníbal Pinto & 1.274 & 885 & 30 \\
\hline Carlos Condell & 16 & 14 & 482 \\
\hline Sargento Aldea & 317 & - & - \\
\hline José F. Vergara & - & 165 & \\
\hline
\end{tabular}

Fuente: Dirección, 1920, pp. 108-109.

Para tener una impresión de la población que estaba bajo la dependencia de la Compañía de Salitres de Antofagasta, contamos con el Censo 1920, que refiere de las oficinas de la Compañía lo que sigue (Tabla 1).

La política de paralizar temporalmente algunas oficinas, para posibilitar el abaratamiento de los costos y la viabilidad empresarial, se hizo manifiesta en el primer quinquenio de la década de 1920. Política que, a su vez, posibilitó la reconstrucción de la Oficina Puelma, a finales de 1922, y la terminación de la Oficina Vergara (FSA, v. 16: 3).

\section{La Compañía de Salitres y su entorno en la posguerra}

Los 10 ańos que abarca el período a estudiar nos muestran la acción de un directorio que guía a la empresa hacia los cambios en la relación con sus trabajadores, empleados y obreros, al calor tanto de los acuerdos empresariales como de la legislación nacional. Aspectos que reflejan la crisis del período del liberalismo económico que había dominado gran parte de la vida empresarial salitrera. El paso de los ańos nos revelan el funcionamiento interno de las oficinas ante los desafíos de las materias primas y la complementación de insumos con otras instalaciones. Se valora también el rol que asumen los científicos y los ingenieros en los años de coyuntura, proceso que abre la posguerra mundial. Es un período que comienza a definir ciclos de bonanza y crisis más agudos que la etapa anterior a 1914, que condujo a la crisis terminal del ciclo salitrero de la década de 1920. Prueba de estos ciclos fue la decisión de la compañía de acogerse a la Ley de Auxilio Salitrero, de septiembre de 1917 , con el fin de mantener su producción, solicitando al Fisco 4 millones de pesos y dejando en prenda un millón de quintales de salitre (FSA, v. 13: 3).

La empresa va a modificar su estrategia empresarial entre fines de la década de 1910 e inicios de 1920. En esta fase, debió encarar los desafíos de la innovación, de acuerdo al modelo Shanks vigente -que introdujo Santiago Humberstone-, del que tuvo noticia en enero de 1885 y que, desde esa fecha, buscó las alternativas al modelo tecnológico dominante (González Pizarro, Lufin Varas, Galeno Ibaceta, 2014), frente a la aguda competencia entre los productores de salitre en Chile y el sostenido desafío del salitre sintético, desde la Primera Guerra Mundial. En noviembre de 1918, la compañía desestimó la invitación de Lord Southbough y del profesor Sandner, en representación del Sindicato Industrial del Nitrógeno, para que se integrara al sindicato, que procuraba "que todos los productores de salitre natural y sintético marchen unidos para ayudarse, evitando la competencia". El rechazo a esta invitación se debía a que la compañía buscaba la "asociación de todos los salitreros chilenos para colocarse en situación de lucha especialmente con los elementos que se interpongan al porvenir de nuestros productos" (FSA, v. 13: 4). 
Es importante acercarnos a las miradas sobre la noción de innovación que se puede aplicar a la empresa en cuestión. Sabido es que el economista austríaco J. Schumpeter incorporó este concepto en su obra Teoría del desarrollo económico, de 1911, aplicándola a las dimensiones directivas, organizativas y técnicas, precisando que el concepto, muy polisémico por lo demás, podía significar por lo menos cinco aspectos: "Introduction of a new good; Introduction of a new Method of Production; Opening of a New Market; Conquest of a new source of supply of raw material son half manufactured goods; Implementation of a new form of organization" (Godin, 2008).

Importante en la visión schumpeteriana fue la diferenciación entre la invención, resultado de un acto de creatividad intelectual, y la innovación, como una decisión económica. En esta perspectiva señaló la relevancia de la innovación tecnológica -la denominada creación destructora- la que debería resolver los problemas de la empresa y poder competir con ventajas para sobrevivir. En palabras suyas, la innovación tecnológica es "a new combination of means of production, that is, as a change in the factors of production (inputs) to produce products (outputs)" (Schumpeter, en Business Cycles, citado por Godin, 2008).

Nos interesa detenernos para el propósito de este trabajo en la dimensión tecnológica. Por una cuestión de espacio, deberemos abstenernos de abordar el tema de la innovación social que también afectó a la empresa. La Compañía de Salitres de Antofagasta asumió, a nuestro entender, una reestructuración para acometer los desafíos de su entorno, la competencia con otras empresas coincidentes en sus objetivos; es decir, la tarea de reducir los costos y maximizar los beneficios en un mercado internacional absolutamente cambiante. El período en que se despliega la compañía fue de turbulencia social, en el cual dos hitos marcaron la región: la huelga y masacre de la plaza Colón de Antofagasta, en febrero de 1906 (González Pizarro, 2009), cuyos sucesos siguió de cerca (FSA, v. 5: 6), y la masacre de la Oficina San Gregorio, en febrero de 1921 (Recabarren Rojas, 2003).

En los procesos de modernización y de innovación, es posible observar lo que Alfred Chandler va a de- nominar, en contraposición con la mano invisible del mercado, la mano visible, resultado de las acciones llevadas a cabo por las decisiones ejecutivas (desde la gerencia y la administración) de una empresa para mejorar su posición en el mercado y en su entorno.

Estas condicionantes, el desafío de la productividad y la reestructuración de la división del trabajo hicieron posible la transformación o adaptación de la Compañía de Salitres. En tal sentido, Alfred Chandler plantea la noción de la mano visible para apuntar a las innovaciones en la administración y la coordinación cotidiana de la producción y la distribución y no a la influencia de los mecanismos del mercado. El planteamiento del historiador norteamericano en torno a las jerarquías administrativas, los ejecutivos asalariados y el significado de los cambios tecnológicos permiten contar con este acervo teórico para examinar la coyuntura de la Compañía de Salitres de Antofagasta. Esto nos ilustra sobre su organización para sortear las dificultades de la producción de nitrato y la colocación del producto en los mercados, como el frente externo, e introducir un reordenamiento del funcionamiento de la empresa, donde se aprecia la influencia de las ideas de Fayol en el papel que debe tomar la gerencia y las distintas secciones administrativas en el frente interno.

Importa de las ideas de Chandler la insistencia en los altos directivos y mandos medios, en el organigrama de la empresa moderna. En palabras suyas:

Modern business enterprise is easily defined: it contains many distinct operating units and it is managed by a hierarchy of salaried executives. Each unit within the modern multiunit enterprise has its own administrative office. Each is administered by a fulltime salaried manager. Each has its own set of books and accounts which can be audited separately from those of the large enterprise. Each could theoretically operate as an independent business Enterprise (Chandler, 1999, pp. 1-3 y Figure 1).

La consideración de la dirección superior (Top $M a$ nagement), la gestión intermedia (Middle Management) y la gestión inferior (Lower management), con 
las dependencias de supervisores y otros funcionarios asalariados.

Fue en este lapso, 1916-1925, cuando la Compañía de Salitres se constituyó en una empresa multiunitaria. Esto se debió a los cambios que suscitó el descubrimiento de nuevas estacas salitreras, la apertura de nuevas operaciones productivas en el cantón Central, la comparación de los registros de producción en sus usinas industriales y los cambios que experimentaba el ambiente sociopolítico nacional y regional.

Para entender esta inflexión en la Compañía de Salitres, se debe tener presente que a lo largo de su existencia fue expandiéndose no solo en lo que concierne a la producción y venta de nitrato, sino que también debió resolver sobre las propuestas que la Asociación Salitrera de Propaganda planteó a los productores y al gobierno, como ocurrió, por ejemplo, en noviembre de 1917, cuando propuso formar la Asociación de Productores de Salitre de Chile. En esa oportunidad, la compañía mostró su conformidad con "la centralización de las ventas, pero no [la] hubo en lo que se refiere al control y restricción de la producción" (FSA, v. 13: 5). Más tarde, debió afrontar la idea de "ofrecer al Gobierno toda su producción a fin de que éste se entienda directamente con el Comité de Compras que funciona en Londres" (FSA, v. 13:6). Tales planteamientos, que fueron compartidos por otras empresas, condujeron el 10 de enero de 1919 a la creación de la Asociación de Productores de Salitre de Chile, que significó para la compañía someterse a las asignaciones de producción mensuales y sostener ideas para la continuidad de la entidad (FSA, v. 17: 1). En tal sentido, acogió la innovación del departamento de Bienestar Social, en el transcurso de la última década de su funcionamiento, 1920 , cuando la crisis salitrera ya se manifestaba (Artaza Barrios, 2016).

También la compañía debió disponer de secciones para los rubros de adquisición y distribución de las mercaderías con destino al abastecimiento de las pulperías, lo cual implicaba negociar con distintos proveedores a nivel de volumen, precio, transporte, entrega; como de igual modo, la compra de insumos industriales para el reemplazo o la reparación de las unidades de maestranza, ferrocarriles, vagones, grúas, motores, etcétera, en las distintas oficinas salitreras.

En este encuadre, la compañía debió acomodar su estructura administrativa a los cambios operados por la tecnología en el nivel productivo. En la industria del nitrato, pueden diferenciarse tres aspectos de la tecnología: uno en el proceso de lixiviación, otro en la energía y otro en el transporte. Fueron tres aspectos que apuntaron a discriminar también el criterio de innovación schumpeteriano, a saber: frente al sistema Shanks, recién se encontró una innovación tecnológica alternativa en el sistema Guggenheim (González Pizarro, 2017, pp. 198-239); un mejoramiento en el método de producción que no se tradujo en una innovación de procesos, como sí fue la introducción de los motores Diesel en las secciones de Casa de Fuerza, y la incorporación de maquinarias y elementos mecánicos en reemplazo de una mayor fuerza laboral de uso manual.

Puede considerarse que en la etapa en que situamos temporalmente nuestro estudio, el modelo de innovación que se verifica es el denominado por Godin como el modelo lineal de innovación ("linear model of innovation"), que transcurre entre principios del siglo XX hasta 1940, y caracterizado "by the ideal of pure science, and people began developing a case for a causal link between basic research and applied research" (Godin, 2005, p. 5). En la historia de la tecnología, como ha recordado Edgerton (2008, p. IX), ésta ha estado vinculada tanto a la invención (en cuanto nueva idea) como a la innovación (su aplicación), empero se ha olvidado que muchas ideas fueron pensadas con mucha antelación para crear nuevas tecnologías que fueron dejadas de lado transitoriamente. Sin embargo, una historia global de la tecnología demuestra que una innovación no ha significado en absoluto dejar obsoleto lo que se usaba al momento del cambio tecnológico. Para Edgerton, el vapor debió modificar el uso del carbón en el siglo XIX, pero se siguió usando incluso más en 1950 que un siglo antes. Todavía seguimos empleando los trenes y los barcos (Edgerton, 2008, p. XI). Los tiempos no siempre son como han sido concebidos por sus contemporáneos. Para este autor, 
Use-centred history is not simply a matter of moving technological time forward... Time was always jumbled up, in the pre-modern era, the post-modern era and the modern era. We worked with old and new things, with hammers and electric drills. In usecentred history technologies do not only appear, they also disappear and reappear, and mix and match across the centuries... Cable TC declined in the 1950s to reappear in the 1980 s... The history of invention and innovation needs to focus on all inventions and innovations at a particular time, independently of their later success of failure. It needs to lok too to invention and innovation in all technologies, not just those favoured by being well known and assumed to be most significant (Edgerton, 2008, pp. XII, XIV).

Estas puntualizaciones permitirán matizar la visión economicista de la noción de innovación, procedente de la tradición schumpeteriana, para acomodarla a los contextos productivos reales, a la mezcla de los tiempos tecnológicos que históricamente -en lo que nos interesa subrayar- no fueron absolutos. En la industria del salitre, el descubrimiento del salitre sintético por Haber-Bosch en 1913 no supuso el cierre de las instalaciones del salitre natural; de igual modo, el surgimiento del procedimiento Guggenheim tampoco se tradujo en la paralización del procedimiento Shanks en las oficinas salitreras, que continuaron hasta 1977 (Bastía, 2014; Wisniak, Garcés, 2001, pp. 429 y 436).

Si nos aproximamos a la Compañía de Salitres desde la perspectiva de su tejido administrativo, podemos señalar que fue "una institución económica que agrupa un conjunto conformado por unidades funcionales y operacionales, administrada por una jerarquía gerencial en diversos niveles" (Coriat y Weinstein, 2011, p. 40). La compañía vivió un proceso de tránsito hacia una estructura jerárquica unitaria o forma de $\mathrm{U}$, de separación vertical de unidades operacionales y la dirección, rodeada de unidades operacionales. Y esto se detecta en la información de las actas del directorio. Como refieren Coriat y Weinstein, esta caracterización primera de la empresa moderna se basa "en el desarrollo de la división del trabajo en la función de gestión mediante la creación de departamentos especializados. Esta organización favorece la explotación de economías de escala, la división del trabajo y la racionalización de la producción” (Coriat y Weinstein, 2011, p. 42).

\section{La Compañía de Salitres de Antofagasta: la modernización de su estructura}

Antes de la Primera Guerra Mundial, la companía acostumbró delegar en una sola persona la responsabilidad de los bienes instalados tanto en el puerto de Antofagasta como en la pampa. Un reflejo de esta política pudo apreciarse cuando se eligió a Francisco Dowd, en 1906, como administrador de la compañía, "en la elaboración del salitre, y dirección técnica de la oficina del Puerto, y dependerá directamente del Consejo de Valparaíso. Administrará directamente la oficina de Carmen Alto y propondrá la planta de empleados al Directorio. Como Administrador en Antofagasta servirá de agente en todo lo relacionado con embarques, desembarques o proveedores de víveres a las oficinas". Su contrato era por tres ańos (FSA, v. 5: 7). Aquello reflejaba todavía la carencia de una división del trabajo radicado en profesionales a cargo de secciones, distinguiendo las operaciones de producción de las de transporte.

La competencia profesional de Dowd fue reconocida por J. Berkwood Hobsbawm en su visita a las salitreras en 1918, donde le encontró como administrador de la Oficina Bella Vista, ensayando un método de lixiviación (Hobsbawm, 1993, p. 581).

La empresa separó las funciones entre los propietarios y la organización administrativa. Fue el primer signo de modernización. Seguidamente, instaló en los ámbitos productivos y administrativos un cuerpo de profesionales destacados, que afianzó las decisiones técnicas. La autonomía que se aprecia entre las decisiones de cada una de las secciones de la estructura empresarial y la microestructura de cada una de las unidades productivas -en este caso, oficinas salitreras- nos sitúa en los rasgos que Alfred Chandler asigna al proceso del cambio de la estructura organizacional de cara a la nueva estrategia que debe acometer la empresa. Ya no basta acordar en 
las Combinaciones las cuotas de producción o bien cerrar una oficina para abrir otra cercana a terrenos de mejor ley. Se trata de encarar el desafío dual de la introducción del salitre sintético en Europa y las innovaciones sectoriales en el proceso productivo del salitre (uso de energía, clase de transporte, mecanización, etc.). En este contexto, la Compañía de Salitres exhibe un planteamiento en el cual la Junta de Accionistas elige a sus consejeros y directivos, por un año. Un ejemplo lo tenemos en la sesión celebrada el 20 de abril de 1925:

Constitución del Directorio. En vista de que la Junta General de Accionistas celebrada hoy, reeligió a los Directores que cumplían su periodo, Srs. Julio Pereira, Manuel Ossa, Carlos Barroilhet y Germán Riesco, y ratificó el nombramiento del Sr. Carlos del Campo, como Director de la Compañía; el Directorio procedió a constituirse y, por unanimidad, fueron designados como Presidente y Vice-Presidente los Srs. Alberto Bascunán Montes y Carlos Barroilhet, respectivamente. Pasó a presidir el Sr. Bascuñán Montes (FSA, v. 18: 1).

Es el Directorio el que formula ante la Junta de Accionistas la política industrial y su coyuntura para la empresa, como lo estableció de tiempo en tiempo - podría indicarse que aproximadamente cada cuatro años-, exponiendo una visión de conjunto, como pudo apreciarse, por ejemplo en 1924, cuando el gerente de la compañía, Sr. Barroilhet, presentó el panorama de tal diseńo:

Politica industrial. De la exposición leída por el Presidente de la Asociación de Productores de Salitre en la última Junta General deduce el Sr. Barroilhet los siguientes hechos fundamentales:

1. El consumo mundial de salitre chileno no ha aumentado proporcionalmente al aumento de consumo de los productos nitrogenados.

2. Nuestra materia prima, es decir, las calicheras, se va agotando con relación a la intensidad de su explotación, y
3. El costo de elaboración va aumentando de día en día.

Como estos tres factores obran directamente en contra del porvenir de la industria salitrera, limitando su libre desarrollo y expansión, considera que es un deber estudiar detalladamente cada uno de ellos para ver modos de aminorar sus efectos. Después de analizar cada uno de estos factores llega a la conclusión de que para conservar la cuota del salitre chileno en el mercado mundial, es necesario sostener i, si es posible, bajar su precio de venta. Para ello indica dos caminos: uno sería la rebaja del costo de exportación, y el otro, la disminución del costo de elaboración por la aplicación científica y sistemática de los métodos modernos de trabajo. Entra en seguida, a estudiar el costo de elaboración de sus oficinas y deduce que, a Extracción le corresponde el 39,5\%, a Transporte el 17\% y a Elaboración el $32 \%$. Por otra parte, el $53,5 \%$ del costo son jornales y el $17,8 \%$ combustible.

Entre otras medidas que podría llevarse a la práctica enumera las siguientes:

1. Adopción de pescantes a vapor o eléctrico para facilitar la explotación de calicheras hondas.

2. Dotar a cada caldera con los aparatos de control necesarios para determinar la marcha científica de los fuegos y contratar un especialista que se encargue de su aplicación.

3. Adaptación de los calderos para el empleo de carbón pulverizado, lo que permitirá usar en condiciones favorables el carbón nacional.

4. Electrificación de todas las líneas de la pampa, $y$

5. Adopción de un tipo adecuado de camión para reemplazar a las carretas. 
Politica de elaboración. Para obtener el máximum de eficiencia económica, recomienda distribuir la cuota de producción de la Compañía en el menor número de oficinas, eligiendo aquellas que produzcan a menor costo, tomando en cuenta la calidad de los caliches, la capacidad de la máquina y los elementos de trabajo. Termina manifestando la conveniencia de ir pensando en la formación de reservas en valores efectivos, independientes de la industria (FSA, v. 17: 2).

Las facultades provistas al gerente por el Consejo se extienden hasta la contratación de empréstitos, como lo solicitado a The Law Debenture Corporation Limited, de Londres, para la construcción de una nueva oficina salitrera en Salinas Norte, el ensanche de la Oficina José Francisco Vergara y Oficina Condell, constituyendo hipotecas sobre todas sus oficinas salitreras, en octubre de 1924.

La configuración de una estrategia empresarial no solo implicaba una razonada exposición, a veces liderada por uno de los principales integrantes del directorio, sino una detallada situación de cada oficina salitrera por parte del inspector delegado ante el directorio, que era complementada por el administrador general (Figura 1).

En concordancia con lo anterior, el inspector delegado, después de dar cuenta del estado de las oficinas Puelma, Edwards, Ossa, Pinto, Prat, Condell, Aldea y Vergara, indicaba el ritmo de la producción, el volumen de stock a estimar y la necesaria acción de paralizar por algunos meses determinadas oficinas o bien poner en marcha otras, con el fin de hacer coincidir producción y precios de mercados. En el transcurso del primer lustro del decenio de 1920, esta estrategia se aplicó continuamente, por ejemplo, paralizando la Oficina Edwards a fines de año, poniendo nuevamente en marcha la Oficina Puelma a principios de enero, deteniendo las faenas en la Oficina Ossa a fines de año para reanudar la elaboración en el mes de julio.

El directorio elabora la política de la empresa apoyada en una estructura que combina las distintas

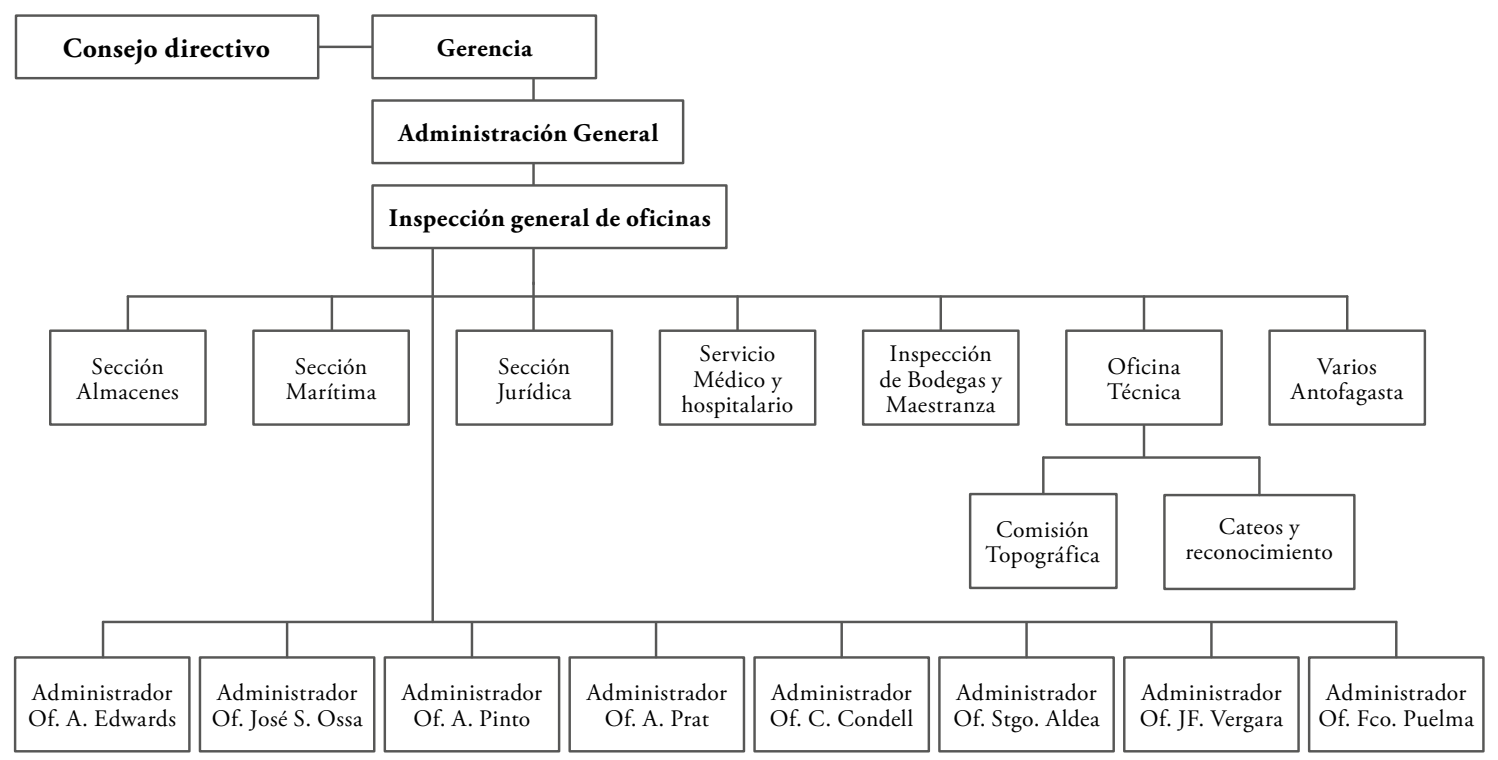

Figura 1. Diagrama de la estructura empresarial de la Compañía de Salitres de Antofagasta. Fuente: Elaboración propia sobre la base de las actas del directorio. 
funciones del proceso productivo, enlazando las estrictamente técnicas con las médico-sociales, las de transporte, las de venta, como unidades supervisoras de tales tópicos sobre el conjunto total de las unidades productivas. Es la constatación de las Proposiciones 1 y 2 de Chandler. En tal sentido, el directorio designó semestralmente inspectores visitadores de toda la pampa salitrera, los que revisaban, anotaban y sugerían reformas en su funcionamiento. En cada oficina salitrera, con su propia estructura análoga que se observa en el organigrama (Tabla 2 ), se toman decisiones autónomas en cuanto al mejoramiento del rendimiento de la producción en conexión con los insumos con que cuenta o debiese incorporar. Una clara muestra de la Propuesta 2 de Chandler.

Tabla 2. Organigrama de las secciones de la Cía. de Salitres de Antofagasta.

\begin{tabular}{|l|c|}
\hline \multicolumn{1}{|c|}{ Gerencia } & Sueldos \\
\hline Gerente & $\$ 6.666,66$ \\
\hline Inspector Delegado & $\$ 6.666,66$ \\
\hline Inspector Delegado & $\$ 5.000$ \\
\hline Contador & $\$ 1.700$ \\
\hline Tenedor de Libros & $\$ 1.450$ \\
\hline Secretario & $\$ 1.180$ \\
\hline Cajero & $\$ 1.150$ \\
\hline Acciones & $\$ 900$ \\
\hline Salitre & $\$ 750$ \\
\hline Ayudante & $\$ 600$ \\
\hline Ayudante & $\$ 575$ \\
\hline Ayudante & $\$ 550$ \\
\hline Ayudante & $\$ 500$ \\
\hline Ayudante & $\$ 450$ \\
\hline Ayudante & $\$ 400$ \\
\hline Abogado & $\$ 600$ \\
\hline Mayordomo & $\$ 1700$ \\
\hline Mozos & $\$ 225$ \\
\hline Mozos & $\$ 170$ \\
\hline Ascensor & $\$ 170$ \\
\hline
\end{tabular}

\begin{tabular}{|c|c|c|c|}
\hline Administración & Sueldo & Asignación & Total \\
\hline $\begin{array}{l}\text { Administrador } \\
\text { General }\end{array}$ & $\$ 5.000$ & $\$ 1.000$ & $\$ 6.000$ \\
\hline $\begin{array}{l}\text { Ayudante } \\
\text { (en Comisión) }\end{array}$ & $\$ 1.600$ & $\$ 1.600$ & $\$ 3.200$ \\
\hline $\begin{array}{l}\text { Secretario } \\
\text { Abogado }\end{array}$ & $\$ 1.666,66$ & & $\$ 1.666,66$ \\
\hline Contador & $\$ 1.900$ & & $\$ 1.900$ \\
\hline Tenedor de Libro & & $\$ 950$ & $\$ 950$ \\
\hline Cajero & $\$ 800$ & $\$ 100$ & $\$ 900$ \\
\hline $\begin{array}{l}\text { Dibujante y } \\
\text { Estadístico }\end{array}$ & $\$ 900$ & & $\$ 900$ \\
\hline Corresponsal & $\$ 800$ & & $\$ 800$ \\
\hline $\begin{array}{l}\text { Ayudante } \\
\text { Cajero }\end{array}$ & $\$ 500$ & & $\$ 500$ \\
\hline $\begin{array}{l}\text { Ayudante } \\
\text { Contabilidad }\end{array}$ & $\$ 450$ & & $\$ 450$ \\
\hline $\begin{array}{l}\text { Ayudante } \\
\text { Contabilidad }\end{array}$ & $\$ 400$ & & $\$ 400$ \\
\hline Escribiente & $\$ 400$ & & $\$ 400$ \\
\hline $\begin{array}{l}\text { Ayudante } \\
\text { Escritorio }\end{array}$ & $\$ 250$ & & $\$ 250$ \\
\hline Junior & $\$ 180$ & & $\$ 180$ \\
\hline Mozo & $\$ 350$ & & $\$ 350$ \\
\hline $\begin{array}{l}\text { Inspección ge- } \\
\text { neral de oficinas }\end{array}$ & Sueldo & Asignación & Total \\
\hline $\begin{array}{l}\text { Inspector } \\
\text { General }\end{array}$ & $\$ 4.166,67$ & $\$ 833,33$ & $\$ 5.000$ \\
\hline $\begin{array}{l}\text { Ingeniero de } \\
\text { Extracción }\end{array}$ & $\$ 1.450$ & $\$ 500$ & $\$ 1.950$ \\
\hline $\begin{array}{l}\text { Inspector de } \\
\text { Contabilidad }\end{array}$ & $\$ 1000$ & $\$ 350$ & $\$ 1.350$ \\
\hline Sub-inspector & $\$ 750$ & $\$ 300$ & $\$ 1.100$ \\
\hline $\begin{array}{l}\text { Sub-inspector } \\
\text { Pulperías }\end{array}$ & $\$ 700$ & $\$ 350$ & $\$ 1.050$ \\
\hline Química & $\$ 700$ & $\$ 300$ & $\$ 1.000$ \\
\hline Escribiente & $\$ 225$ & $\$ 300$ & $\$ 525$ \\
\hline \multicolumn{2}{|c|}{ Sección Almacenes } & Sueldo & Total \\
\hline \multicolumn{2}{|c|}{ Cotizador y Comprador } & $\$ 1.900$ & $\$ 1.900$ \\
\hline \multicolumn{2}{|l|}{ Facturero } & $\$ 600$ & $\$ 600$ \\
\hline
\end{tabular}




\begin{tabular}{|c|c|c|}
\hline Bodeguero & $\$ 600$ & $\$ 600$ \\
\hline Ayudante de Bodega & $\$ 250$ & $\$ 250$ \\
\hline Junior & $\$ 180$ & $\$ 180$ \\
\hline Sección Marítima & Sueldo & Total \\
\hline Jefe de Sección & $\$ 3.000$ & $\$ 3.000$ \\
\hline Ayudante & $\$ 1.300$ & \\
\hline Despachador Aduana & $\$ 1.000$ & $\$ 1.000$ \\
\hline Tenedor de Libro & $\$ 900$ & $\$ 900$ \\
\hline Jefe Descarga & $\$ 900$ & $\$ 900$ \\
\hline Pesador de salitre & $\$ 750$ & $\$ 750$ \\
\hline Pasatiempo & $\$ 600$ & $\$ 600$ \\
\hline Corresponsal & $\$ 600$ & $\$ 600$ \\
\hline Cobrador y Cuentas Corrientes & $\$ 600$ & $\$ 600$ \\
\hline Entregador de Playa & $\$ 600$ & $\$ 600$ \\
\hline Liquidaciones y reclamos & $\$ 550$ & $\$ 550$ \\
\hline Empleado de bahía & $\$ 550$ & $\$ 550$ \\
\hline Agencia de vapores & $\$ 500$ & $\$ 500$ \\
\hline Servicio Judicial & Sueldo & Total \\
\hline Abogado en Antofagasta & $\$ 1.000$ & $\$ 1.000$ \\
\hline Abogado en Tocopilla & $\$ 250$ & $\$ 250$ \\
\hline Abogado en Iquique & $\$ 300$ & $\$ 30$ \\
\hline Procurador & $\$ 150$ & $\$ 150$ \\
\hline Varios en Antofagasta & Sueldo & Total \\
\hline Encargado & $\$ 1.300$ & $\$ 1.300$ \\
\hline Jefe de maestranza & $\$ 950$ & $\$ 950$ \\
\hline Jefe de serenos & $\$ 500$ & $\$ 500$ \\
\hline
\end{tabular}

\begin{tabular}{|c|c|c|c|}
\hline $\begin{array}{l}\text { Inspección } \\
\text { de Bodegas y } \\
\text { Maestranzas }\end{array}$ & Sueldo & Asignación & Total \\
\hline $\begin{array}{l}\text { Inspector } \\
\text { General }\end{array}$ & $\$ 4.166,67$ & $\$ 833,33$ & $\$ 5.000$ \\
\hline Ingeniero Jefe & $\$ 3000$ & $\$ 500$ & $\$ 3.500$ \\
\hline $\begin{array}{l}\text { Jefe de } \\
\text { Maestranza } \\
\text { Central }\end{array}$ & $\$ 1.200$ & $\$ 300$ & $\$ 1.500$ \\
\hline $\begin{array}{l}\text { Jefe Talleres } \\
\text { Maestranza } \\
\text { Central }\end{array}$ & $\$ 550$ & & $\$ 550$ \\
\hline Contador & $\$ 750$ & $\$ 350$ & $\$ 1.100$ \\
\hline Bodeguero & $\$ 400$ & $\$ 300$ & $\$ 700$ \\
\hline $\begin{array}{l}\text { Ayudante de } \\
\text { Bodeguero }\end{array}$ & $\$ 200$ & $\$ 300$ & $\$ 500$ \\
\hline Pasatiempo & $\$ 225$ & $\$ 300$ & $\$ 525$ \\
\hline Oficina Técnica & Sueldo & Asignación & Total \\
\hline Ingeniero Jefe & Sin datos & Sin datos & Sin datos \\
\hline $\begin{array}{l}\text { Ingeniero } \\
\text { Ayudante }\end{array}$ & $\$ 1.500$ & $\$ 500$ & $\$ 2.000$ \\
\hline $\begin{array}{l}\text { Ingeniero } \\
\text { Electricista }\end{array}$ & $\$ 1.000$ & $\$ 500$ & $\$ 1.500$ \\
\hline $\begin{array}{l}\text { Ingeniero } \\
\text { Auxiliar }\end{array}$ & $\$ 400$ & $\$ 300$ & $\$ 700$ \\
\hline Dibujante & $\$ 350$ & $\$ 300$ & $\$ 650$ \\
\hline Dibujante & Sin datos & Sin datos & Sin datos \\
\hline $\begin{array}{l}\text { Comisión } \\
\text { Topográfica }\end{array}$ & Sueldo & Asignación & Total \\
\hline Topógrafo & $\$ 1.000$ & $\$ 500$ & $\$ 1.500$ \\
\hline Ayudante & $\$ 400$ & $\$ 300$ & $\$ 700$ \\
\hline Ayudante & $\$ 400$ & $\$ 300$ & $\$ 700$ \\
\hline Ayudante & $\$ 400$ & $\$ 300$ & $\$ 700$ \\
\hline
\end{tabular}




\begin{tabular}{|c|c|c|c|}
\hline $\begin{array}{l}\text { Cateos y } \\
\text { Reconocimiento }\end{array}$ & Sueldo & Asignación & Total \\
\hline Ingeniero & $\$ 1.000$ & $\$ 500$ & $\$ 1.500$ \\
\hline $\begin{array}{l}\text { Servicio } \\
\text { Médico y } \\
\text { Hospitalario }\end{array}$ & Sueldo & Asignación & Total \\
\hline Médico Jefe & $\$ 1.600$ & $\$ 1.600$ & $\$ 3.200$ \\
\hline $\begin{array}{l}\text { Médico en } \\
\text { Antofagasta }\end{array}$ & $\$ 500$ & & $\$ 500$ \\
\hline Farmacéutico & $\$ 1.000$ & & $\$ 1.000$ \\
\hline $\begin{array}{l}\text { Practicante } \\
\text { Hospital Oficina } \\
\text { Puelma }\end{array}$ & $\$ 620$ & & $\$ 620$ \\
\hline $\begin{array}{l}\text { Practicante } \\
\text { Oficina Edwards }\end{array}$ & $\$ 550$ & & $\$ 550$ \\
\hline $\begin{array}{l}\text { Practicante } \\
\text { Oficina Ossa }\end{array}$ & $\$ 550$ & & $\$ 550$ \\
\hline $\begin{array}{l}\text { Practicante } \\
\text { Oficina Condell }\end{array}$ & $\$ 550$ & & $\$ 550$ \\
\hline $\begin{array}{l}\text { Practicante } \\
\text { Oficina Aldea }\end{array}$ & $\$ 550$ & & $\$ 550$ \\
\hline $\begin{array}{l}\text { Matrona } \\
\text { Hospital Puelma }\end{array}$ & $\$ 700$ & & $\$ 700$ \\
\hline $\begin{array}{l}\text { Matrona Oficina } \\
\text { Edwards }\end{array}$ & $\$ 500$ & & $\$ 500$ \\
\hline $\begin{array}{l}\text { Matrona Oficina } \\
\text { Condell }\end{array}$ & $\$ 500$ & & $\$ 500$ \\
\hline $\begin{array}{l}\text { Matrona Oficina } \\
\text { Aldea }\end{array}$ & $\$ 500$ & & $\$ 500$ \\
\hline $\begin{array}{l}\text { Matrona Oficina } \\
\text { Ossa }\end{array}$ & $\$ 500$ & & $\$ 500$ \\
\hline Dentista & -- & $\$ 350$ & $\$ 350$ \\
\hline $\begin{array}{l}\text { Oficina A. } \\
\text { Edwards }\end{array}$ & Sueldo & Asignación & Total \\
\hline Administrador & $\$ 1,600$ & $\$ 1.600$ & $\$ 3.200$ \\
\hline Contador & $\$ 750$ & $\$ 350$ & $\$ 1.100$ \\
\hline Cajero & $\$ 600$ & $\$ 300$ & $\$ 900$ \\
\hline Pasatiempo & $\$ 500$ & $\$ 300$ & $\$ 800$ \\
\hline Bodeguero & $\$ 400$ & $\$ 300$ & $\$ 700$ \\
\hline $\begin{array}{l}\text { Ayudante de } \\
\text { Escritorio }\end{array}$ & $\$ 225$ & $\$ 300$ & $\$ 525$ \\
\hline Corrector & $\$ 650$ & & $\$ 650$ \\
\hline $\begin{array}{l}\text { Jefe de } \\
\text { Maestranza }\end{array}$ & $\$ 550$ & & $\$ 550$ \\
\hline $\begin{array}{l}\text { Jefe de } \\
\text { Elaboración }\end{array}$ & $\$ 550$ & & $\$ 550$ \\
\hline Ensayador & $\$ 650$ & & $\$ 650$ \\
\hline Pulpería & $\$ 300$ & $\$ 145$ & $\$ 445$ \\
\hline
\end{tabular}

\begin{tabular}{|c|c|c|c|}
\hline Oficina J.S.Ossa & Sueldo & Asignación & Total \\
\hline Administrador & $\$ 1.600$ & $\$ 1.600$ & $\$ 3.200$ \\
\hline Contador & $\$ 750$ & $\$ 350$ & $\$ 1.100$ \\
\hline Cajero & $\$ 600$ & $\$ 300$ & $\$ 900$ \\
\hline Pasatiempo & $\$ 500$ & $\$ 300$ & $\$ 800$ \\
\hline Bodeguero & $\$ 400$ & $\$ 300$ & $\$ 700$ \\
\hline Cajero Pulpería & $\$ 275$ & $\$ 300$ & $\$ 575$ \\
\hline $\begin{array}{l}\text { Auxiliar } \\
\text { Escritorio }\end{array}$ & $\$ 150$ & $\$ 300$ & $\$ 450$ \\
\hline Corrector & $\$ 650$ & & $\$ 650$ \\
\hline $\begin{array}{l}\text { Ingeniero } \\
\text { Mecánico }\end{array}$ & $\$ 700$ & $\$ 300$ & $\$ 1.000$ \\
\hline Jefe Elaboración & $\$ 550$ & & $\$ 550$ \\
\hline Ensayador & $\$ 400$ & & $\$ 400$ \\
\hline Pulpería Tienda & $\$ 525$ & $\$ 175$ & $\$ 700$ \\
\hline $\begin{array}{l}\text { Pulpería } \\
\text { Despacho }\end{array}$ & $\$ 300$ & $\$ 175$ & $\$ 475$ \\
\hline $\begin{array}{l}\text { Oficina Carlos } \\
\text { Condell }\end{array}$ & Sueldo & Asignación & Total \\
\hline Administrador & $\$ 1.600$ & $\$ 1.600$ & $\$ 3.200$ \\
\hline Contador & $\$ 750$ & $\$ 350$ & $\$ 1.100$ \\
\hline Pasatiempo & $\$ 500$ & $\$ 300$ & $\$ 800$ \\
\hline $\begin{array}{l}\text { Auxiliar } \\
\text { Escritorio }\end{array}$ & $\$ 150$ & $\$ 300$ & $\$ 450$ \\
\hline Corrector & $\$ 650$ & & $\$ 650$ \\
\hline $\begin{array}{l}\text { Jefe de } \\
\text { Maestranza }\end{array}$ & $\$ 550$ & & $\$ 550$ \\
\hline Jefe Elaboración & $\$ 550$ & & $\$ 550$ \\
\hline Pulpería & $\$ 300$ & $\$ 150$ & $\$ 450$ \\
\hline
\end{tabular}

Fuente: Acta de la Sesión Ordinaria del Consejo Directivo de la Compañía de Salitres de Antofagasta, celebrada en Valparaíso, el 30 de diciembre de 1922.Libro de Actas de la Compañía de Salitres de Antofagasta, vol.16

La capacidad de resolución -y cierta autonomía- del administrador general queda de manifiesto cuando informa al directorio de los traslados o construcciones de oficinas:

Se dio a conocer los detalles enviados por el Administrador General relativo a los costos aproximados que representarían a la Compañía el ensanche y traslado de las oficinas "Edwards" y "Condell" y la terminación de 
la "Puelma" y la "Vergara", que en resumen serían como sigue: Traslado oficina "Condell” a los terrenos de Cuevitas \$2.500.000; Aumento de 6 cachuchos y traslado de la oficina "Edwards" al estacamento Salinas Norte \$ 5.000.000; Obras por ejecutar en la oficina "Puelma" \$ 1.430.000; Obras por ejecutar en la oficina "Vergara" \$3.700.000" (FSA, v. 17: 2a).

La incidencia del parecer del administrador general sobre cada una de las oficinas salitreras, es un hecho que se puede rastrear desde 1915 (FSA, v. 11:3).

De igual modo, cada administrador de una oficina salitrera contó con las facultades para tomar decisiones sobre reparaciones, maquinarias y ponderación de los terrenos calicheros, costos y modalidades de explotación (FSA, v. 11:4).

La incidencia del personal altamente cualificado siempre estuvo presente en la administración de la compañía. En 1923, por ejemplo, el jefe de la Sección Marítima planteó una reforma de la planta de profesionales que fue apoyado por el administrador general (FSA, v. 16: 4). Otra prueba de la Proposición 5 de Chandler. Este último personero, ese mismo año, llamó la atención sobre la falta de un mayor número de empleados superiores: "Actualmente hay distribuidos entre el puerto y las oficinas 12 ingenieros, número del todo insuficiente para hacer frente a la intensificación de los trabajos de construcción y a la puesta en marcha de diversas oficinas. Propone la contratación de siete ingenieros, de éstos, cinco deberán contratarse a la brevedad posible" (FSA, v. 16: 5). Otro campo de acción de los ingenieros, además de su gestión en los Ferrocarriles del Estado (Guajardo Soto, 2015).

De esta manera, la planta de ingenieros reforzaría las secciones siguientes: de la Administración General (administrador general y ayudante del administrador general), de la Inspección General de Oficinas (inspector general, subinspector, ingeniero ayudante -palas y perforadoras-, ingeniero ayudante -cateos-, ingeniero ayudante-levantamiento-), Inspección de Bodegas y Maestranzas (inspector general, ingeniero jefe de Maestranza Central, ingeniero segundo), Ofi- cinas (administrador y subadministrador del Grupo "Puelma-Aldea", igual para el Grupo "Pinto-Prat", administradores Oficinas Edwards, Ossa, Condell), Reconstrucción Oficina Francisco Puelma (Dos ingenieros auxiliares), Terminación Oficina José Francisco Vergara (ingeniero jefe). Este delineamiento apuntó a que la resolución técnica de cada oficina pudiese resolverse de modo más descentralizado, en cuanto a racionalizar la mano de obra, la producción o adquisición de insumos.

Una última modificación apuntó a la introducción del "Escribiente de pampa" en el escalafón de personal de escritorio en las oficinas, incorporando a un empleado encargado de la estadística (FSA, v.16: 6). La nomenclatura definía al funcionario intermediario entre el personal de pampa y el Escritorio, teniendo como jefes inmediatos a los jefes de Sección y al jefe de Pampa. Sus funciones consisten en llevar "un archivo ordenado de todas las estadísticas y documentos de extracción y acarreo, hará las denuncias de accidentes conforme a los datos que proporcionará el Jefe de Sección, atenderá los reclamos, llevará un libro por orden alfabético de todos los obreros de pampa, etc." (Macuer, 1930, p. 164).

La Compañía de Salitres de Antofagasta tuvo una incidencia en la economía regional de Antofagasta, tanto por la contratación de gran parte de su personal como de la provisión de mercaderías para sus pulperías del comercio local. La importancia del salitre en la ciudad de Antofagasta se tradujo en que los jóvenes profesionales egresados del Instituto Comercial, creado en 1906, pudieron insertarse en la estructura administrativa de la industria salitrera y, principalmente, la Escuela Industrial del Salitre, fundada en 1918, impulsada por el empresario salitrero y político Augusto Bruna, y dirigida por el ingeniero de minas Horacio Meléndez, que entregaba luego de tres años de estudios el título de "Conductores de trabajos mineros y salitreros" y ofrecía la práctica en las oficinas de la Compañía de Salitres de Antofagasta (Panadés y Ovalle, 1994). Clara demostración de la Proposición 8 de Chandler. Bruna era quien se había asociado con Pascual Baburizza y Lukinovic, en 1913, sociedad de la que se retiró en 1917, cuando fue elegido senador por Antofagasta del Partido Radical. Formó parte de la comisión consultiva del salitre que el gobierno formó en 1918. 


\section{La Compañía de Salitres de Antofagasta: la búsqueda de la innovación como estrategia}

La estrategia de innovación que se observa no obedece solo al agotamiento de los terrenos donde están los pedimentos de la compañía. También se buscaba mejorar la relación costo/beneficio de la actividad extractiva, de la chancadora al de lixiviación, y proyectar el tiempo útil de una oficina salitrera. En este lineamiento, lo importante fue procurar la innovación tecnológica. Sin embargo, hay que diferenciar la innovación en los medios productivos. No solo lo que afecta al proceso de lixiviación que, en el sistema Shanks, va a estar asociado a las máquinas chancadoras, sino que también habrá que considerar otros medios o insumos que van a afectar el costo/beneficio; entre otros, el uso del petróleo como fuente de energía y la introducción de las locomotoras Diesel en vez de aquellas que usaban vapor. De igual modo, se podrá observar una combinación de herramientas: el trabajo de los cueveros con el uso de barretas o la introducción de martillos hidráulicos. Las oficinas de la época, incluidas las que usaban el sistema Shanks, operaban con esta combinación de materiales y mano de obra basada fundamentalmente en la experiencia, desde los denominados particulares que removían el apartado del caliche de la masa trabajada por los barreteros. En la pampa salitrera, convivían oficios altamente especializados con otros sin calificación.

Sobre el período, Cariola y Sunkel han mostrado la paradoja que se evidenció, pues al no haber cambios tecnológicos fundamentales y en virtud de la disminución de las "leyes de los caliches las cantidades de salitre elaboradas por persona tienden más bien a bajar, por lo que la tendencia del empleo, a crecer" (Cariola-Sunkel, 1991, p. 83).

En el campo tecnológico, centraremos nuestra atención en los esfuerzos por introducir inventos en el sistema productivo de la compañía e incorporar mejoras en el sistema de transporte.

En el sistema productivo, hubo interés de la companía por buscar experimentos que pudiesen mejorar el sistema Shanks, como también producir elemen- tos derivados del nitrato, para abrir la oferta en el mercado. De igual manera, se conjugaron elementos novedosos en un ambicioso plan de producir maquinarias para la industria salitrera.

Patricio Díaz ha hecho notar la preocupación brindada por la Compañía de Salitres de Antofagasta acerca del proceso de extracción del yodo. Incluso antes de separarse de la Compañía de Salitres y Ferrocarriles de Antofagasta, uno de sus principales accionistas, el ingeniero Francisco Puelma, patentó determinados procedimientos en 1874 y 1882 (Díaz, 2005, p. 16), aunque esta última patente se basaba en el proceso del químico francés Ch. Robert de la Mahotière (Crozier, 1993, p. 196).

Al despuntar el siglo XX, la compañía prosiguió en la búsqueda de inventos que plantearan alternativas al modelo Shanks. En 1907 le solicitó a su administrador en Antofagasta, Francisco Dowd, que visitara la Oficina Castilla, donde se experimentaba el sistema Nordenflycht, e informara sobre éste (FSA, v. 5: 8a). Dos años después, mostró interés en el procedimiento Gabella, logrando convenir con la comunidad de mismo nombre una inversión de 5 mil pesos que "demuestre la bondad del invento". De lo contrario, se le debía reembolsar dicho capital (FSA, v. 6: 1).

Desde 1912, el directorio de la compañía comenzó a escuchar la conveniencia de incorporar nuevos métodos de extracción de caliche. El director, Sr. Aliband, planteó emplear explosivos en lugar de pólvora y adoptar el uso de perforadores mecánicos, "que permiten preparar los caliches, abriéndolos, antes de entregárselos a los particulares. Cree, además, que el sistema actual, de fraccionar en pequeños trozos el caliche en la pampa, hace perder, en los llampo que produce el respaldeo [sic] de las colpas, una porción considerable de buen caliche, y que estas operaciones es más racional hacerlas en las máquinas -en las ramplas de las oficinas- donde todo puede ser aprovechado, trabajando con fuerza mecánico". Una vez que se probara su conveniencia se iba a resolver. (FSA, v. 12: 2).

En diciembre de 1915 se introdujeron los filtros Butters, que dieron buenos resultados al "conseguir dejar las borras con solo $1 \frac{1}{2} \%$ de ley" (FSA, v. 11: 
5). Sin embargo, no se obtuvieron similares alcances para tener caliche acendrados del Salar del Carmen, por lo que se descartó hacer experimentos en la región (FSA, v. 11: 6).

En 1917 la compañía decidió incorporar las nuevas calderas marca Balcock \& Wilcox en la Oficina José F. Vergara, para lo cual se contrató al ingeniero especialista George Lewellin (FSA, v. 13: 10). De igual manera, se vio la conveniencia de contar con energía eléctrica en la sección que la empresa tenía en el puerto de Antofagasta (FSA, v. 13: 11). Ese año, se contrató en Europa a Emilio Gobbi, por cuenta del señor Ricardo Ariztía, para someter a experiencia un procedimiento de su invención destinado a mejorar sustancialmente el sistema de elaboración del salitre. También planteó crear una oficina central de estudios. Su trabajo se extendió hasta octubre de 1919 (FSA, v. 18: 9).

En febrero de 1918, el directorio tomó nota de las gestiones que se llevaban a cabo con "el Gobierno para la fabricación y exportación de maquinarias para salitreras y que, aunque esto va muy lento, una vez que se resuelva habría facilidades para obtener lo que se necesita” (FSA, v. 13:12). Empero, lo que consignaba el acta no daba más noticia sobre qué clase de maquinarias se tenía en proyecto y tampoco se volvió a tocar el tema en el directorio. Aquello hubiese constituido una situación disruptiva en el funcionamiento empresarial en Chile (Ducoing, 2016).

En 1918 se tomó contacto con Roberto Nordenflycht para que, "por vía de ensayo, y por el término de uno o dos meses, manufacturara en nuestras oficinas varios derivados del salitre, proporcionándole los elementos y personal que estime necesarios, de acuerdo con el Administrador General". Esto daría a la compañía una "nueva orientación de negocios, ya que se presta a un gran desarrollo en caso de cumplirse las expectativas" (FSA, v. 13: 7). En agosto ya había producido 30 mil kilos semanales de soda cristalizada y de 5 mil o 6 mil kilos de cenizas de soda, pero todavía no se había normalizado la elaboración (FSA, v. 13: 8). Empero, los costos de tales ensayos llevaron al directorio a "tomar precauciones para no incrementar demasiado los desembolsos".
En noviembre de 1918 hubo buenas noticias para el directorio, pues tuvo información del método Prache y Bouillon, "nuevo procedimiento para elaborar salitre económicamente", cuyos ensayos ha seguido de cerca la administración de la pampa. El interés de la compañía se tradujo en contratar a un técnico para que informara y eventualmente invertir en el procedimiento (FSA, v. 13: 9).

Sin embargo, en la visita que hizo la comisión establecida por el gobierno en 1918, encabezada por Alejandro Bertrand y J. B. Hobsbawm, a las oficinas de la Compañía de Salitres de Antofagasta, no percibieron novedades en la producción del caliche. En general, la industria del salitre se mostró con variaciones "que existían entre las máquinas de las diferentes oficinas, adaptadas a la calidad de los caliches, y las innovaciones en cada caso" (Hobsbawm, 1993, p. 569).

Cuatro ańos después, en noviembre de 1922, una propuesta del Sr. Holstein para "hacer experiencias con los caliches borrosos del Salar del Carmen" (FSA, v. 16: 7) terminó con la sequía de inventos.

En febrero de 1923, al saberse de los ensayos practicados en la Oficina Castilla por parte del Sr. Arturo Poupin, que implicaban un nuevo procedimiento, el directorio apoyó su adopción, considerando que ofrecía las siguientes ventajas:

1. Eliminación de las pérdidas de nitrato contenidos en las borras que en el sistema actual se acumula. 2. Supresión de las pérdidas provenientes del nitrato que queda sin disolverse en el centro de los trozos de salitre que se botan con el ripio. Suponiendo un rendimiento de $66 \%$, estima un $22 \%$ las pérdidas que se eliminan con su sistema de elaboración, la que permitirá tratar materiales de baja ley. Otra de las ventajas de su procedimiento es que se aprovechan íntegramente los elementos actuales del sistema Shanks, y para verificar el proceso completo, no es necesario modificar toda la máquina, pues cada cachucho constituye una unidad, tratándose 3 cachuchos para una marcha continua. 
La semejanza entre el sistema Shanks y el nuevo llevó al administrador general a solicitar al "inventor presente planos de transformación para nuestras oficinas". El director Ossa argumentó que en las oficinas alemanas se habían ensayado procedimientos semejantes al de Poupin con resultados prácticos. También en la Oficina Delaware se había aplicado el sistema Allen, con mucho interés (FSA, v.16: 8). Un nuevo contrato con el Sr. Poupin, en abril, incorporó algunas ideas de Ossa y se aplicó en la Oficina Condell (FSA, v. 16: 9).

En la sesión del 11 de noviembre de 1922, uno de los directores de la compañía, Manuel Ossa, planteó la imperiosa necesidad de establecer "en nuestras oficinas una sección de investigación experimental a cargo de él, para que después de un año de estudios prácticos y teóricos, proponga una reforma del sistema actual a un nuevo procedimiento combinado con el actual". Los restantes directores consideraron que la investigación tan vasta era mejor plantearla a la Asociación de Productores de Salitre de Chile (FSA, v. 16: 10). A raíz de la visita de la comisión consultiva del salitre, en octubre de 1918, se fundó el Instituto Científico e Industrial del Salitre, precisamente para investigar innovaciones tecnológicas. En ese contexto, el ingeniero Belisario Díaz Ossa planteó en enero de 1922 la necesidad de revisar la ley de patente en los inventos, que debía "reservarse exclusivamente a la verdadera invención, es decir, a la creación de algo que no existía antes y debe tener además un carácter industrial tangible y palpable y estar caracterizada por la novedad u originalidad y por la veracidad”, expuesto en la revista Caliche, Órgano del Instituto Cientifico e Industrial del Salitre: materias que hemos examinado en otro lugar (González Pizarro, 2016, pp. 34-55).

Un nuevo procedimiento de elaboración fue debatido por el directorio en abril de 1923: el del Sr. Daniel Claro Lastarria, sin mayores efectos (FSA, v. 16: 11). No pasó lo mismo con el procedimiento Vidaurre, con el cual se celebró un contrato, similar al de Poupin, en mayo de 1923 (FSA, v. 16: 12). En cuanto al invento de Poupin, en junio de 1923 se adaptaron tres cachuchos al sistema en la Oficina Condell (FSA, v. 16: 13).
Finalmente, en noviembre de 1923, se pudo tener la noticia técnica del procedimiento Guggenheim. Exposición que realizó el ingeniero Belisario Díaz Ossa, encomendado por el gobierno "con el objeto de que se declare legalmente instalada la patente", en la Asociación de Productores de Chile. Para la compañía, se estaba en presencia de un sistema de elaboración a temperaturas bajas -menos de 60 grados-, por el cual:

Se introduce en el proceso sales que se denominan estabilizadoras, porque se sabe que a esas temperaturas las leyes de disolución de los nitratos, sulfatos y cloruro no permite una disolución adecuada del nitrato, lo que sí sucede a las temperaturas altas del actual procedimiento de elaboración. Los estabilizadores potasio, magnesio y calcio son, pues, muy importantes en el procedimiento y deben ser controlados constantemente para que su presencia en la disolución realice el objetivo para, como consecuencia, se necesite durante todo el proceso el empleo de personal técnico bien competente y que debe estar continuamente preocupado de analizar los caldos para saber lo que debe hacerse.

Se hizo notar que la mano de obra era cara, el proceso de 70 horas era exagerado y el capital de instalación, considerable. La ventaja frente al sistema Shanks no era muy significativa, en cuanto al rendimiento del petróleo. No se sabía el precio de costo de la unidad de salitre y se consideraba que aún debía perfeccionarse "para que llegue a ser eficiente y económico" (FSA, v. 17: 4).

Sin embargo, la compañía no cejó en procurarse alternativas al sistema tecnológico Shanks y, en junio de 1924, pudo enterarse de otro invento, el de Prudhomme, que había dado resultados en la elaboración de sales potásicas en Pintados. El directorio de la compañía fue de la idea de que se hicieran controles sobre la experiencia por espacio de dos o tres meses, antes de tomar una resolución. Importante fue conocer de la existencia de una sociedad que apoyaba tales experimentos, por lo que consideró poder involucrarse en ella con una participación del $25 \%$ del negocio, o sea, un millón de pesos "que se invertirán 
en una de nuestras oficinas en gran escala el sistema Prudhomme" (FSA, v. 17: 5). Por otra parte, los resultados del invento Poupin en el tratamiento de los finos y sales del ripio hicieron pensar a la compañía "que el procedimiento puede aplicarse con ventajas en combinación con el sistema Shanks" (FSA, v. 17: 6). En septiembre de 1924 se recibió con satisfacción la noticia de que la "Sociedad Industrial y Comercial del Salitre", que auspiciaba el sistema Prudhomme, había expresado las condiciones para asociar a la Compañía de Salitres de Antofagasta con la cuarta parte del capital. La compañía solicitó los estatutos y la estadística, para resolver definitivamente (FSA, v. 17: 7).

En enero de 1925, la compañía autorizó al administrador general para que cargara a la cuenta "Provisión para Reparaciones” todos los gastos ocasionados por las experiencias del sistema Poupin llevadas a cabo en la Oficina Condell, y los derivados de las experiencias Prudhomme en la Oficina Mosquitos (FSA, v. 17: 8).

En cierta forma, las negociaciones llevadas con The Lautaro Nitrate para su fusión detuvieron los experimentos señalados, quedando éstos a nivel de inventos y no de innovación.

Uno de los temas que constituye una preocupación fundamental en toda labor minera, es el agua. La industria salitrera no escapó a esta preocupación. Fue costumbre que el abastecimiento de agua fuese surtido por la Empresa del Ferrocarril de Antofagasta a Bolivia y quedase a su arbitrio el valor a cobrar. Sin embargo, hubo situaciones donde lo convenido entre las partes no satisfizo la demanda. En 1904 hubo dificultades por parte de la empresa del FF.CC. para proveer agua desde Polapi, lo cual obligó a la Compañía de Salitres a buscar alternativas. Dentro de las opciones, la principal fue solicitar una merced de aguas al gobierno en el río Loa. En 1905, la compańía inició las gestiones para tal cometido. La solicitud fue tramitada y el intendente de Antofagasta "decretó la concesión conforme a la ley". La compañía buscó entre los ingenieros de la empresa del FF.CC.: Julio Pinkas, para hacerse cargo del proyecto, y Josiah Harding, para tender la cañería desde el río Loa hasta Lomas Bayas (FSA, v. 5: 9). El agua fue uno de los temas más controversiales de la época, cuyo abastecimiento a las oficinas salitreras controló la empresa de los Ferrocarriles de Antofagasta a Bolivia (Blakemore, 1996, pp. 103-114).

En septiembre de 1915 un informe solicitado al abogado Luis Claro Solar, sobre las mercedes de agua en el río Loa, aconsejó a la compañía, en circunstancias que el gobierno había suspendido las concesiones, que ésta "aprovechara estas aguas abriendo pozos cerca del río en las propiedades mineras que tiene en las inmediaciones, lo que es amparado por el artículo 9 del Código de Minería”. Sin embargo, Claro Solar advertía la necesidad de respetar lo dispuesto en el artículo 20 del mismo código, que prohibía abrir calicatas a menos de 100 metros de canales, acueductos, etcétera (FSA, v. 11: 7). Desde 1918 se manejaron proyectos ingenieriles para obras de mejoramiento de la captación de aguas, tanto de los pozos como el de San Francisco, como de los piques de Carmen Alto, Santa Rosa y Buitre que surtieron a las oficinas Puelma, Condell y Aldea (FSA, v. 13: 13).

Una idea interesante fue planteada, en septiembre de 1922, por el presidente del directorio: establecer en el salar del Carmen -exactamente en la estación O'Higgins, a solo $30 \mathrm{~km}$ del puerto de Antofagastalas bodegas de depósito de todo el salitre producido por la compañía, como también del carbón y materiales de consumo. En su concepto, "unidas así las oficinas, el salitre sería traído del interior sin ensacar, tomándolo de las propias canchas, y se verificarían en el salar tanto la ensacadura como su entrega al ferrocarril de Antofagasta. Como ventajas del proyecto se veía una economía en los fletes, cesación de los seguros que gravan el salitre y un mayor control de las existencias en las diferentes oficinas". Sin embargo, el administrador general hizo notar lo inviable del proyecto en lo económico, por los costos involucrados (FSA, v. 16: 14). En noviembre se volvió a tocar el asunto del ensacado, proponiéndose sacos con oreja en las cuatro esquinas para evitar el empleo de los ganchos. Era una idea aplicada por la Compañía El Loa, pero no se pudo desterrar el uso de los ganchos, una costumbre inveterada en esta labor (FSA, v. 16: 15). Mejores resultados se obtuvieron con la introducción de la pala mecánica en las faenas calicheras (FSA, v. 16: 16). 
Nuevas innovaciones, como equipo para soldaduras eléctricas y la incorporación de la pala a vapor para la extracción del caliche, mostraron que no siempre iban unidas al éxito. Las palas a vapor fallaron por la defectuosa preparación del terreno, la mala organización del trabajo o por los defectos de la misma pala, concluía un informe que tuvo presente el directorio para desechar dicha máquina (FSA, v. 16: 17). Lo mismo acaeció con la prueba para quemar carbón pulverizado en el locomóvil, que fracasó (FSA, v. 16: 18). Lo que sí resultó un éxito fue el uso de los 10 motores eléctricos para acendradoras y cintas para la Oficina Puelma, en diciembre de 1923 (FSA, v. 16: 9).

En septiembre de 1924 se pudo constatar adelantos en las comunicaciones, con la instalación de la radiotelefonía y la radiotelegrafía en todas las oficinas de la compañía (FSA, v.17: 10).

Las innovaciones en el transporte fueron importantes. El trabajo de las denominadas "carretas vareras", tiradas por mulas, que llevaban el caliche desde las canchas a las máquinas de elaboración, que había constituido el transporte tradicional desde los inicios de la industria salitrera regional, comenzaban su retiro. La necesidad de reemplazar a las mulas chúcaras -que debían ser amaestradas para su incorporación a las faenas- se planteó con fuerza en el segundo semestre de 1924. El director Manuel Ossa abogó por la "utilización de medios mecánicos para el transporte de caliche a las máquinas de elaboración”. Opinión que fue compartida en el seno del directorio de la compañía (FSA, v.17: 11).

La implantación exitosa de un tipo de camión común en las faenas calicheras, conforme a un plan propuesto por el gerente, en octubre de 1924, significaba el fin de la fuerza animal y de las carretas.

Lo que hizo la compañía en el ámbito de los medios de transporte fue mejorarlos, no a partir de una innovación sino, por el contrario, acogiendo lo que ya había en el mercado y se estaba empleando en las oficinas más avanzadas de la industria salitrera en general. En lo que concierne a insumos nuevos, puede indicarse una preocupación desde 1915, de incorporar más locomotoras en el puerto como respaldo, debido al gran movimiento comer- cial y previendo cualquier trastorno, o bien para ser destinadas, al comenzar 1916, a la Oficina Condell (FSA, v. 11:8).

En agosto de 1918, considerando el volumen de exportación de salitre, se estimó de utilidad comprar cuatro lanchas o faluchos para el trabajo en los muelles (FSA, v. 13: 14). De esta manera, la introducción de los vehículos mecánicos cerró un ciclo de medios de transporte de tracción animal en la industria del salitre y la disminución de los costos de producción.

\section{La fusión entre la Compañía de Salitres de Antofagasta y The Lautaro Nitrate Company Limited en 1925}

La relación entre Pascual Baburizza y la Compañía de Salitres de Antofagasta databa desde febrero de 1909, cuando la compañía solicitó un préstamo al empresario croata. La cantidad de 2 millones de pesos hizo que Baburizza transformara la deuda en acciones de la Compañía de Salitres. Las ganancias de las acciones incrementaron su participación en la empresa chilena hasta noviembre de 1912, cuando las vendió. Fue el primer encuentro de Baburizza con el mundo salitrero. Al año siguiente, en 1913, la sociedad entre Baburizza, Bruna y Lukinovic compró al Banco de Chile la Compañía Salitrera Progreso de Antofagasta, controlando las oficinas Ausonia, Filomena y Aconcagua, además del puerto de Mejillones.

En 1923, en razón de la fusión de las Compañías Salitreras Lautaro y Lastenia -esta última donde tenía acciones Baburizza-, surgió The Lautaro Nitrate Company Ltd, convirtiéndose el empresario croata en su principal propietario (Torres Dujisin, 2003, pp. 35-43)

Desde comienzos de 1925, se comenzó a tratar en el directorio la fusión con The Lautaro Nitrate $\mathrm{C}^{\circ}$ Ltd., para la que, miembros de ambas compañías, desde el mes de marzo "recorrían las oficinas de la pampa buscando todos los datos e informaciones necesarias para determinar y establecer con la ma- 
yor aproximación posible, los valores comparativos de las dos compañías en lo que respecta a sus terrenos, maquinarias y elementos de trabajo" (FSA, v. 18: 1). Hubo obstáculos, principalmente por parte de The Lautaro Nitrate, en la parte contable. De común acuerdo, ambas empresas debían examinar los resultados de los ańos 1923 y 1924 , pero dado lo reciente de la creación de The Lautaro, no se disponía en detalle de tal información. Lo mismo sucedió respecto a las cubicaciones de terrenos, donde no había planos de cateos, por lo que se suplió con cifras globales. La valorización de las oficinas tuvo que ser realizada por los seńores Ayala y Letelier de la Compañía de Salitres, "por estimación personal en cuanto a los terrenos y para las oficinas adoptar como procedimiento la comparación individual de las oficinas de la Compañía Lautaro con las nuestras por asimilación de sus elementos de trabajos, maquinarias, campamentos y demás instalaciones”. Después, se hizo la comparación de los costos de producción y de cancha para los ańos en referencia (FSA, v. 18: 1). A fines de mayo de 1925 , la comisión de la Compañía de Salitres encargada de la fusión analizó el contrainforme de The Lautaro, sobre la valorización de ambas empresas. La reunión se verificó en la oficina de Agustín Edwards, pues éste había enviado una carta el 29 de mayo a ambas compañías, exponiendo su criterio y haciéndose cargo de las diferencias de valorización. A su parecer, "se ha formado el convencimiento de que subsiste como desacuerdo inamovible de valorización una suma que asciende alrededor de 600.000 libras esterlinas". Su propuesta era compartir la cifra, y se reconociera a la Compañía de Salitres el 60\% y a la Lautaro el $40 \%$, con lo cual "la diferencia a favor de nuestra compañía será de 360.000 libras que debería entregarse en acciones" ( FSA, v. 18: 2). A esto se agregaría un $40 \%$ de incentivo sobre la cifra, que correspondería al "premio con que se cotizan en el mercado de Londres las acciones de la Lautaro, lo que, en definitiva, representa la suma de 504.000 libras".

El consejo directivo -en esta ocasión integrado por Carlos Barroilhet, Puelma Besa, García Pereira, Ossa, Fernández García Riesco, Del Campo y el inspector delegado de la compañía- se inclinaron por acoger la propuesta de Edwards, siempre y cuando el valor se elevara a 600 mil libras, entregándose las
504 mil en dinero y la diferencia en acciones. Contrarios a esta solución se manifestaron Fernández García Riesco y Manuel Ossa. Este último fundamentó su negativa recogiendo la trayectoria de la Compañía de Salitres y el significado que había alcanzado para la región y para Chile:

Está en discusión una nueva proposición que viene a mejorar las condiciones para vender esta Compañía a una empresa netamente extranjera y, por consiguiente, ir de lleno a la desnacionalización de la industria salitrera. Hoy he podido comprender las bases fundamentales que han tenido los señores Directores para ir de una manera tan violenta a una liquidación. Mi sorpresa llega a su punto culminante cuando se tiene en manos todos los antecedentes comerciales, que no son halagadores. ¿Qué motivos fundamentales hemos tenido para justificar, siquiera en parte, el paso trascendental que vamos a dar? En mi concepto no se justifica comercialmente y de ninguna manera se justifica bajo el punto de vista de los intereses nacionales. Hay algo más grande en la criatura humana que rechaza de lleno toda negociación, por provechosa que sea, cuando está en nuestra conciencia que ella no consulta, sino que es eminentemente perjudicial a los intereses generales del país... Lo que hoy es comercialmente bueno para unos pocos, puede traer consecuencias tremendas para los que heredan nuestros nombres. Es original y único lo que está pasando en estos momentos. Con el corazón ligero vamos a hacer desaparecer la empresa más grande y netamente chilena que jamás, entiéndanlo bien, jamás haya existido en el país. Si hay algo que dé una alta medida de nuestra capacidad industrial como chilenos, ese algo lo constituye la Compañía de Salitres de Antofagasta... Demos por terminada toda gestión y dediquemos nuestros esfuerzos a darle mayor vida y prosperidad. No entreguemos con ánimo ligero a elementos extranjeros lo que nosotros hemos probado poder administrar y desarrollar con mayor acierto que esos mismos elementos, pues, hasta hace poco, 
nos creían incapaces de llevar a términos grandes empresas con nuestros solos esfuerzos (FSA, v. 18: 2. Destacados nuestros).

Sin embargo, el consejo no varió su decisión. Siguió examinando los artículos del convenio con The Lautaro, preocupado por las interpretaciones de algunos de ellos.

Durante la sesión del 5 de junio, el directorio -a propuesta de la comisión encargada de negociar la fusión- acordó aceptar las 550 mil libras esterlinas como monto en valor que recibirían los accionistas en dinero efectivo, "dinero que se tomará de los fondos de reserva de la Compañía, disminuyéndose así el patrimonio vendido" (FSA, v. 18: 3).

El 26 de junio se verificó la Junta General Extraordinaria de Accionistas de la Compañía de Salitres de Antofagasta, donde fue aprobado el proyecto de fusión. Se designó en la ocasión a los señores Carlos Barroilhet, Julio Pereira y Carlos del Campo para representar a la compañía en el contrato de venta. El traspaso de la propiedad de la Compañía de Salitres de Antofagasta a Pascual Baburizza, representante de The Lautaro Nitrate Company Ltd, se verificó ante el notario de Valparaíso Arturo Bascuñán Cruz. El día 11 de julio de 1925, se firmó la escritura pública de venta del activo y pasivo de la companía a The Lautaro Nitrate Company Limited. Con este acto desapareció la principal empresa salitrera chilena (FSA, v. 18: 4). La venta de la Compañía de Salitres alcanzó la cifra de 2.560.000 libras esterlinas.

Ese mismo día sábado, 11 de julio, la comisión mencionada se constituyó en carácter de liquidadores de la Compañía de Salitres de Antofagasta, giró el monto indicado de la venta en favor de The Lautaro para pagar las 512 mil acciones de esta empresa, que en ese mismo acto suscribió la Junta Liquidadora a nombre de los accionistas. Ese mismo día, 11 de julio, el gerente de la Compañía de Salitres giró la suma de $5.489 .189,56$ pesos, para hacer frente a las siguientes obligaciones:

1. Pagar el dividendo de 2.80 pesos por acción que se distribuirá el 15 de julio: $\$$ 5.376.000,00 pesos.
2. Pagar saldos de distribución de acciones: $\$ 32.126,12$ pesos.

3. Pagar estampillas para recibos de dividendos: $\$ 90.00$ pesos.

4. Comprar acciones Antofagasta a fin de facilitar a los accionistas la operación de canje y para gastos generales: $\$ 80.000 .00$ pesos.

En la segunda sesión de la Junta Liquidadora (FSA, v. 18:5), dio cuenta del pago de dividendos y la venta de letras, así como de las gestiones de The Lautaro para que el gobierno aprobara la disolución anticipada de la compañía, "sin cuyo requisito no es posible distribuir a los accionistas las 550.000 libras esterlinas".

Durante las sesiones tercera (FSA, v. 18:6) y cuarta (FSA, v. 18: 7), la Junta Liquidadora se abocó a orientar a aquellos accionistas que deseaban recibir las acciones que les correspondían de The Lautaro y de las transacciones de éstas ante la empresa de Baburizza; de igual modo, a informar en la prensa el listado de accionistas acreditados para los recibos de finiquitos y la indemnización correspondiente a cada uno de los ex directores de la Compañía de Salitres, correspondiéndole 2 mil libras esterlinas a Ramón Puelma Besa, Carlos García, Manuel Ossa R., Manuel Fernández García y Germán Riesco, por no continuar formando parte del Consejo Local en Valparaíso. Edwards percibió la suma de 5 mil libras esterlinas por su mediación en la fusión (Torres Dujisin, 2003, p. 44).

Un asunto que trajo intranquilidad fue la noticia de que el Servicio de Impuestos Internos había cursado orden de pago por 1.298 .000 pesos por concepto de pago a la renta de las 550 mil libras esterlinas. Empero, un informe en derecho de los abogados Arturo Alessandri Rodríguez, Germán Riesco, Pedro N. Montenegro, José M. Ríos y Juan E. Montero esgrimido por la Junta Liquidadora fue rotundo en apuntar a que no "están obligados a pagar suma alguna, como impuesto a la renta, con motivo del reparto entre los accionistas de la Compañía de Salitres de Antofagasta, del producto de la liquidación de la sociedad". Aun cuando el informe entregaba cierta conformidad, la Junta Liquidadora 
sacó a relucir que, en la eventualidad de tener que pagar el impuesto mencionado, éste sería asumido por The Lautaro, como había quedado estipulado en un intercambio epistolar con Pascual Baburizza (FSA, v. 18: 7).

La Junta Liquidadora estuvo en funciones hasta la sesión 14, celebrada el 15 de enero de 1929 (FSA, v.18: 8). La crisis final del salitre coincidía con la liquidación de las últimas acciones vinculadas con la Compañía de Salitres de Antofagasta.

\section{Conclusiones}

En la literatura especializada sobre la industria salitrera no existen estudios que se hayan preocupado por una historia de la empresa. La Compañía de Salitres de Antofagasta se hizo conocida cuando constituyó una sola entidad con la Empresa del Ferrocarril y se vio involucrada en la Guerra del Pacífico. Sin embargo, el período como empresa estrictamente salitrera, que la convirtió en la principal de capitales chilenos en el ciclo salitrero (1886-1925), nos permite comprender de qué modo las concesiones del período boliviano sobre los terrenos salitrales le permitieron acrecentar en el siglo XX el número de oficinas salitreras. $\mathrm{E}$ incluso formar sociedades para la creación de otras compañías salitreras que operaron en el principal cantón salitrero, el boliviano y Central.

La habilidad y competencia del directorio de la empresa, cuyos sucesores de los capitales iniciales, Edwards, Ossa, Puelma, por citar algunos, continuaron con la propiedad, pero la adaptaron a los nuevos desafíos del siglo XX, permitió la transformación de la Compañía de Salitres de Antofagasta en una empresa moderna. La estructura que exhibió, desde la década de 1920, posibilitó enfrentar la coyuntura competitiva ante los propios productores de salitre y ante el mercado mundial, que observó con interés al salitre sintético. Las nuevas ideas sobre la división del trabajo, la incorporación de profesionales altamente cualificados en los mandos superiores y medios de la empresa, con bastante autonomía de resolución, hicieron de la Compañía de Salitres de Antofagasta una de las empresas más modernas de Chile. A esta estructura modernizadora que se adecuó a la estrategia establecida en cuanto a la producción, bajar los costos, enfrentar inversiones para la mejora de los sistemas tecnológicos, le permitió estar al tanto de inventos variados que apuntaron a procurar la anhelada innovación definitiva al sistema Shanks. Empero, la venta de la compañía al industrial croata Pascual Baburizza no solo mostró las habilidades negociadoras de los representantes de la compañía sino sus capacidades de proyección, pues un par de ańos después, la aplicación del sistema Guggenheim vino casi simultáneamente con la crisis definitiva de la industria salitrera, y de la mano de la crisis mundial.

\section{Agradecimientos}

El autor agradece a los evaluadores anónimos las observaciones y sugerencias planteadas que, indudablemente, han mejorado el artículo en cuestión.

\section{Referencias citadas}

Arce, I. (1940). Para mis hijos. Antofagasta, 31 de diciembre. En Archivo Isaac Arce. Escuela de Derecho-Antofagasta. Facultad de Ciencias Jurídicas, Universidad Católica del Norte.

Arce R, I. (2004). Narraciones Históricas de Antofagasta. Antofagasta: Corporación Pro Antofagasta, 1930. Imprenta Moderna.

Artaza Berríos, P. (2016). El reverso del bienestar. La creación del departamento de Bienestar Social y el reforzamiento del control social en el Norte Grande a principios de los años 20. Estudios Atacameños. Arqueología y Antropologia Surandinas, 52, 49-68.

Barros, A. (2015). Revolución chilena, litoral boliviano: La Patria, la Compañía de Salitres y los prolegómenos de la Guerra del Pacífico en el Desierto de Atacama (18701879). Revista de Antropología Experimental, 15, 483-520.

Bastías Saavedra, M. (2014). Nitrate, in: 1914-1918-online. En Daniel, U., Gatrell, P., Janz, O., Jones, H., Keene, J., Kramer, A. and Nasson, B. (Eds.). International Encyclopedia of The First World War. Issued by Freie Universität Berlin, 10-08. Doi:10.15463/ie1418.10228

Blakemore, H. (1996). Historia del Ferrocarril de Antofagasta a Bolivia 1888-1988. Couyoumdjian, J. R. y Kase, B. (Trads.). Santiago: Impresos Universitarios. 
Brown, J. R. (1963). Nitrate Crisis, Combinations and the Chilean government in the Nitrate Age. The Hispanic American Historical Review, 43, 230-246.

Capaldo, A., Damm, D., Odone, C. (2010). Sobre el habitar la Pampa del Toco (1890-1920). Si Somos Americanos. Revista de Estudios Transfronterizos, 10(2), 175-198.

Cariola, C., Sunkel, O. (1991). Un siglo de historia económica de Chile 1830-1930. Santiago: Universitaria.

Comisión Central del Censo. Memoria presentada al Supremo Gobierno Censo Jeneral de 1907. Disponible en www. ine.cl/estadistica/censos/censos_de_población_y vivienda (Consultado 12.05.2017).

Coriat, B., Weinstein, O. (2011). Nuevas teorías de la empresa. Una revisión crítica. Buenos Aires: Lenguaje Claro Editora.

Couyoumdjian, R. (1973-1974). El mercado del salitre durante la Primera Guerra Mundial y la postguerra 19141921. Notas para su estudio. Historia, 12, 13-55.

Crozier, R. D. (1993). La industria del yodo 1815-1915. Historia, 15, 141-212.

Chandler, A. (1999). The Visible Hand. The Managerial Revolution in American Business. Fifteenth Printing. USA: Harvard University Press.

Dirección General de Estadística. Censo de Población de la República de Chile levantado el 15 de diciembre de 1920. Disponible en www.ine.cl/estadistica/censos/censos_de_ población_yvivienda (Consultado 12.05.2017).

Ducoing R., C. (2016). Un siglo de expansión y divergencia. Inversión en maquinaria en una economía periférica. Chile 1830-1938. Revista Semestral Perfiles Económicos, 1, 43-81.

Edgerton, D. (2008). The Shock of the Old. Technology and global history since 1900. Great Britain: Profile Books Ltd.

Godin, B. (2005). The Linear Model of Innovation: The Historical Construction of an Analytical Framework. Project on the History and Sociology of SeT Statistics Working Paper $N^{\circ}$. 30. Disponible en http://www.csiic.ca/ PDF/ (Consultado 22.05.2017).

Godin, B. (2008). In the Shadow of Schumpeter: W. Rupert MacLaurin and the Study of Technological Inno- vation. Project on the Intellectual History of Innovation. Worker Paper $N^{\circ}$ 2. Disponible en http://www.csiic.ca/ PDF/ (Consultado 22.05.2017).

Godin, B. (2015). Models of Innovation: Why Models of Innovation are Models, or What Work is Being Done Calling Them Models? Project on the Intellectual History of Innovation Working Paper $N^{\circ} 22$. Disponible en http:// www.csiic.ca/PDF/ (Consultado 22.05.2017).

González Miranda, S. (2010). El Cantón Bolivia o Central durante el ciclo de expansión del nitrato. Estudios Atacameños. Arqueología y Antropología Surandinas, 52, 49-68.

González Miranda, S. (2013). Las combinaciones salitreras: el surgimiento del empresariado del nitrato en Chile (1884-1910). Diálogo Andino. Revista de Historia, Geografía y Cultura Andina, 42, 41-56.

González Miranda, S., Sossa Rojas, A. (2011). La vida privada de dos campamentos salitreros del cantón Bolivia durante la administración The Lautaro Nitrate Co. Ltd: Ausonia y Filomena. Norte de Chile. Diálogo Andino. Revista de Historia, Geografía y Cultura Andina, 38, 93-110.

González Pizarro, J. A. (2005). Isaac Arce Ramírez, historiador y testigo del ciclo del salitre de Antofagasta. Diálogo Andino, 25, 9-41.

González Pizarro, J. A. (2009). La huelga/masacre de la Plaza Colón: 6 de febrero de 1906 en Antofagasta. Las lecciones para la historia. En Artaza, P., González Miranda, S. y Jiles, J. (Eds.). A cien años de la masacre de Santa María de Iquique (pp. 211-239). Santiago: LOM Ediciones.

González Pizarro, J. A. (2017). La épica del salitre en el desierto de Atacama: 1880-1967. Trabajo, tecnologías, vida cotidiana, conflicto y cultura. Antofagasta: Universidad Católica del Norte / España: Editorial Académica Espańola.

González Pizarro, J. A., Lufin Varas, M., Galeno Ibaceta, C. (2014). Británicos en la región de Antofagasta. Los negocios concomitantes con la minería del desierto de Atacama y sus redes sociales (1880-1930). Estudios Atacameños. Arqueología y Antropologia Surandinas, 48, 175-190.

Guajardo Soto, G. (Comp.) (2014). Innovación y Empresa. Estudios Históricos de España y América Latina. México: Lenguaje Claro. 
Guajardo Soto, G. (2015). Public Works and Business in the Conformation of the Technocracy of Chile during the First Globalization. H-Industri@, 16, 67-78.

Hobsbawm, J. B. (1993). Una visita a las oficinas salitreras en 1918. Introducción, traducción y notas de J. R. Couyoumdjian. Historia, 15, 567-594.

Latcham, R. A. (1926). Chuquicamata Estado Yankee. Santiago: Nascimento.

Macuer Llaña, H. (1930). Manual Práctico de los trabajos en la pampa salitrera. Valparaíso: Salesiana.

Mayo, J. (1979). La Compañía de Salitres de Antofagasta y la Guerra del Pacífico. Historia, 14, 71-102.

Memoria del Delegado Fiscal de Salitreras presentada al Señor Ministro de Hacienda en 1904. Iquique: Tipografía y Litografía de R. Bini e Hijos.

Miller, R. (2015). The British comercial houses in Peru and Chile between the two world war: sucess and failure. Estudios de Economia, 42, 93-119.

Nazer Ahumada, R. (2000). La fortuna de Agustín Edwards Ossandón: 1815-1878. Historia, 33, 369-415

O’Brien, T. (1980). The Antofagasta Company: A Case Study of Peripheral Capitalism. The Hispanic American Historical Review, 1, 1-31.

Ortega, L. (1984). Los empresarios, la política y los orígenes de la guerra del Pacífico. Contribuciones Programa Flacso, 24. Santiago de Chile.

Panadés Vargas, J., Ottorino Ovalle, O. (1994). Antofagasta y los inicios de la Educación Técnica. Hombre y Desierto. Una perspectiva cultural, 8. Universidad de Antofagasta.

Penrose Jr. R. F. (1910). The Nitrate Deposits of Chile. The Journal of Geology, 18(1), 1-32.

Querejazu Calvo, R. (2001). Aclaraciones históricas sobre la guerra del Pacifico. La Paz: Librería Editorial Juventud.

Ravest Mora, M. (1983). La Compañia salitrera y la ocupación de Antofagasta 1878-1879. Santiago: Andrés Bello.

Recabarren Rojas, F. (2003). La matanza de San Gregorio. 1921: crisis y tragedia. Segunda edición. Santiago: LOM Ediciones.
San Francisco, A., Ballester, B., Sepúlveda, J., Lasnibat, M., Sepúlveda, A. (2009). Flor de Chile. Vida y Salitre en el cantón de Taltal. Cuadernos de Historia Marxista, I(3), 3-118.

Semper, y Michells (1908). La industria del salitre en Chile... traducida directamente del alemán y considerablemente aumentada por Javier Gandarillas y Orlando Gigliotto Salas. Santiago de Chile: Imprenta, Litografía y Encuadernación Barcelona.

Silva Narro, D. (1909). Guía Administrativa, Industrial y Comercial de las provincias de Tacna, Tarapacá y Antofagasta. Santiago: Imprenta Gutenberg.

Silva Narro, D. (1914). Guia Administrativa, Industrial y Comercial de las provincias de Tacna, Tarapacá y Antofagasta. Santiago de Chile: Imprenta Gutenberg.

Torres Dujisin, I. (2003). La vida de un croata. Pascual Baburizza Soletic. Valparaíso: Servicio de Imprenta de la Universidad de Playa Ancha.

Tower, W. (1913). The Nitrate fields of Chile. The Popular Science Monthly, september, 83, 209-230 Disponible en: https://en.wikisource.org/w/index.php?title=Popular_ Science_Monthly/Volume_83/September_1913/The_ Nitrate_Fields_of_Chile\&oldid=5639462 (Consultado 20.08.2017).

Vidal, J. (1933). Veinte años después. La tragedia del salitre. Santiago: Sociedad Imp. Universo.

Villegas, A. (2015). El impuesto al salitre y la Guerra del Pacífico. Revista Argumentum, 16, 379-401.

Wisniak, J., Garcés, I. (2001). The rise and fall of the salitre (Sodium Nitrate) industry. Indian Journal of Chemical Technology, 8, 427-438.

\section{Fuentes consultadas}

Archivo Nacional (Santiago de Chile). Fondo del Salitre de Antofagasta (FSA): Libros de Actas de la Compañía de Salitres de Antofagasta:

NB: Algunos libros de actas están extraviados en la actualidad. Los libros de actas tienen doble numeración, una correspondiente en la parte superior que refiere al 
registro del Fondo del Salitre y otra en la parte inferior relativa específicamente a las Actas del Directorio. Citaremos por el correlativo de las actas y entre paréntesis el registro del Fondo.

\section{Volumen 4 (461):}

$\mathrm{N}^{\circ}$ 1: Acta de las Sesiones Ordinarias del Consejo Directivo de la Compañía de salitres de Antofagasta, días 17 y 25 de mayo de 1900.

\section{Volumen 5 (469):}

$\mathrm{N}^{\circ} 1$ : Actas sesiones días 10 de noviembre, 7 de diciembre de 1905 y 15 de marzo de 1906.

$\mathrm{N}^{\circ}$ 2: Actas sesiones días 21 de enero y 22 de diciembre de 1904.

$\mathrm{N}^{\circ}$ 3: Acta sesión día 1 de diciembre de 1904.

$\mathrm{N}^{\circ} 4$ : Actas sesiones días 20 de julio, 24 de agosto y 19 de octubre de 1905 .

$\mathrm{N}^{\circ}$ 5: Actas sesiones días 17 de agosto y 7 de septiembre de 1905 .

$\mathrm{N}^{\circ}$ 6: Acta sesión día 8 de febrero de 1906.

$\mathrm{N}^{\circ} 7$ : Acta sesión día 14 de diciembre de 1906.

NV 8: Acta sesión día 2 de marzo de 1907.

$\mathrm{N}^{\circ} 8 \mathrm{a}$ : Acta sesión día 2 de marzo de 1907

$\mathrm{N}^{\circ}$ 9: Actas sesiones días 1,15 de diciembre de 1904; 2 y 23 febrero, 23 de marzo, 27 de abril y 11 de mayo de 1905 .

Volumen 6 (471):

$\mathrm{N}^{\circ}$ 1: Acta sesión día 12 de junio de 1909.

\section{Volumen 11 (514):}

$\mathrm{N}^{\circ}$ 1: Acta de la sesión día 4 de septiembre de 1915.

$\mathrm{N}^{\circ}$ 2: Actas sesiones días 4 y 18 de diciembre de 1915.

No 3: Acta sesión día 14 de octubre de 1915.

$\mathrm{N}^{\circ}$ 4: Acta sesión día 23 de octubre de 1915.

$\mathrm{N}^{\circ} 5$. Acta sesión día 29 de diciembre de 1915.

$\mathrm{N}^{\circ}$ 6: Acta sesión día 5 de febrero de 1916.

$N^{\circ} 7$ : Acta sesión día 4 de septiembre de 1915.

$\mathrm{N}^{\circ} 8$. Actas sesiones días 4 de septiembre de 1915 y 3 de enero de 1916.

Volumen 12 (495):

$\mathrm{N}^{\circ}$ 1: Acta sesión día 28 de junio de 1912.

$\mathrm{N}^{\circ}$ 2: Acta sesión día 2 de noviembre de 1912.

Volumen 13 (530):

$\mathrm{N}^{\circ}$ 1: Acta sesión día 5 de enero de 1918.
$\mathrm{N}^{\circ}$ 2: Acta sesión día 23 de marzo de 1918.

$\mathrm{N}^{\circ}$ 3: Acta sesión día 5 de enero de 1918.

$\mathrm{N}^{\circ}$ 4: Acta sesión día 9 de noviembre de 1918.

$\mathrm{N}^{\circ}$ 5: Acta sesión día 5 de enero de 1918.

$\mathrm{N}^{\circ}$ 6: Acta sesión día 8 de junio de 1918.

$\mathrm{N}^{\circ} 7$ : Acta sesión día 1 de junio de 1918.

$\mathrm{N}^{\circ}$ 8: Acta sesión día 24 de agosto de 1918.

$\mathrm{N}^{\circ}$ 9: Acta sesión día 9 de noviembre de 1918.

$\mathrm{N}^{\circ}$ 10: Acta sesión día 15 de diciembre de 1917.

$\mathrm{N}^{\circ}$ 11: Acta sesiones día 15 de diciembre de 1917; día 18 de noviembre de 1922.

$\mathrm{N}^{\circ}$ 12: Acta sesión 23 de febrero de 1918.

$\mathrm{N}^{\circ}$ 13: Acta sesión día 16 de febrero de 1918.

$\mathrm{N}^{\circ}$ 14: Acta sesión día 3 de agosto de 1918.

Volumen 16 (572):

$\mathrm{N}^{\circ}$ 1: Acta sesión día 4 de noviembre de 1922.

$\mathrm{N}^{\circ}$ 2: Acta sesión día 3 de marzo de 1923.

$\mathrm{N}^{\circ} 2^{2}$. Acta sesión día 9 de agosto de 1924.

$\mathrm{N}^{\circ}$ 3: Acta sesión día 16 de diciembre de 1922.

$\mathrm{N}^{\circ}$ 4: Acta sesión día 17 de marzo de 1923.

$\mathrm{N}^{\circ}$ 5: Acta sesión día 24 de marzo de 1923.

Nº: Acta sesión día 2 de abril de 1923.

$\mathrm{N}^{\circ}$ 7: Acta sesión día 4 de noviembre de 1922.

$\mathrm{N}^{\circ}$ 8: Acta sesión día 24 de febrero de 1923.

$\mathrm{N}^{\circ}$ 9: Acta sesión día 14 d abril de 1923.

$\mathrm{N}^{\circ}$ 10: Acta sesión día 11 de noviembre de 1922.

$\mathrm{N}^{\circ}$ 11: Acta sesión día 21 de abril de 1923.

$\mathrm{N}^{\circ} 12$. Acta sesión día 5 de mayo de 1923.

$\mathrm{N}^{\circ}$ 13: Acta sesión día 16 de junio de 1923.

$\mathrm{N}^{\circ}$ 14: Acta sesión día 23 de septiembre de 1922.

$\mathrm{N}^{\circ}$ 15: Acta sesión día 11 de noviembre de 1922.

N 16: Acta sesión día 3 de marzo de 1923.

$\mathrm{N}^{\circ}$ 17: Acta sesiones días 14 y 21 de abril, 21 de julio de 1923.

N 18: Acta sesión día 21 de abril de 1923.

\section{Volumen 17 (576):}

$\mathrm{N}^{\circ}$ 1: Acta sesión día 25 de agosto de 1923.

$\mathrm{N}^{\circ}$ 2: Acta sesión día 25 de octubre de 1924.

$\mathrm{N}^{\circ}$ 3: Acta sesión día 9 de agosto de 1924.

$\mathrm{N}^{\circ}$ 4: Acta sesión día 17 de noviembre de 1923.

$\mathrm{N}^{\circ}$ 5: Acta sesión día 14 de junio de 1924.

$\mathrm{N}^{\circ}$ 6: Acta sesión día 24 de agosto de 1924.

$\mathrm{N}^{\circ}$ 7: Acta sesión día 13 de septiembre de 1924.

No 8: Acta sesión día 17 de enero de 1925.

$\mathrm{N}^{\circ}$ 9: Acta sesión día 1 de diciembre de 1923. 
$\mathrm{N}^{\circ}$ 10: Acta sesión 13 de septiembre de 1924.

$\mathrm{N}^{\circ}$ 11: Acta sesión 23 de agosto de 1924.

Volumen18 (594):

$\mathrm{N}^{\circ}$ 1: Acta sesión de 6 de mayo de 1925.

$\mathrm{N}^{\circ} 2$ : Acta sesión de 30 de mayo de 1925.

$\mathrm{N}^{\circ} 3$ : Acta sesión de 5 de junio de 1925.

№4: Acta sesión 11 de julio de 1925.

$\mathrm{N}^{\circ}$ 5: Acta sesión 7 de agosto de 1925.

$\mathrm{N}^{\circ}$ 6: Acta sesión 14 de agosto de 1925.

$\mathrm{N}^{\circ} 7$ : Acta sesión 4 de septiembre de 1925.

$\mathrm{N}^{\circ}$ 8: Acta sesión 15 de enero de 1929. 